OPEN ACCESS

Edited by:

Jodi Pawluski,

University of Rennes 1, France

Reviewed by:

Sohye Kim,

University of Massachusetts Medical

School, United States

David A. Slattery,

University Hospital

Frankfurt, Germany

*Correspondence:

Teodora Georgescu

teodora.georgescu@otago.ac.nz

Rosemary S. E. Brown

rosie.brown@otago.ac.nz

Specialty section

This article was submitted to Women's Mental Health

a section of the journal

Frontiers in Global Women's Health

Received: 30 August 2021 Accepted: 01 November 2021 Published: 01 December 2021

Citation:

Georgescu T, Swart JM, Grattan DR and Brown RSE (2021) The Prolactin Family of Hormones as Regulators of Maternal Mood and Behavior Front. Glob. Womens Health 2:767467.

doi: 10.3389/fgwh.2021.767467

\section{The Prolactin Family of Hormones as Regulators of Maternal Mood and Behavior}

\author{
Teodora Georgescu 1,2,3*, Judith M. Swart ${ }^{1,2,3}$, David R. Grattan ${ }^{1,2,4}$ and \\ Rosemary S. E. Brown ${ }^{1,3 *}$ \\ ${ }^{1}$ Centre for Neuroendocrinology, University of Otago, Dunedin, New Zealand, ${ }^{2}$ Department of Anatomy, School of Biomedical \\ Sciences, University of Otago, Dunedin, New Zealand, ${ }^{3}$ Department of Physiology, School of Biomedical Sciences, University \\ of Otago, Dunedin, New Zealand, ${ }^{4}$ Maurice Wilkins Centre for Molecular Biodiscovery, Auckland, New Zealand
}

Transition into motherhood involves profound physiological and behavioral adaptations that ensure the healthy development of offspring while maintaining maternal health. Dynamic fluctuations in key hormones during pregnancy and lactation induce these maternal adaptations by acting on neural circuits in the brain. Amongst these hormonal changes, lactogenic hormones (e.g., prolactin and its pregnancy-specific homolog, placental lactogen) are important regulators of these processes, and their receptors are located in key brain regions controlling emotional behaviors and maternal responses. With pregnancy and lactation also being associated with a marked elevation in the risk of developing mood disorders, it is important to understand how hormones are normally regulating mood and behavior during this time. It seems likely that pathological changes in mood could result from aberrant expression of these hormone-induced behavioral responses. Maternal mental health problems during pregnancy and the postpartum period represent a major barrier in developing healthy mother-infant interactions which are crucial for the child's development. In this review, we will examine the role lactogenic hormones play in driving a range of specific maternal behaviors, including motivation, protectiveness, and mother-pup interactions. Understanding how these hormones collectively act in a mother's brain to promote nurturing behaviors toward offspring will ultimately assist in treatment development and contribute to safeguarding a successful pregnancy.

Keywords: prolactin, placental lactogen (PL), prolactin receptor, maternal behavior, maternal mood, neuroendocrinology, neural circuitry

\section{INTRODUCTION}

The birth of immature offspring in mammalian species necessitates a period of intensive and prolonged caregiving by parents. In a number of species, including humans, and some primate and rodent species, fathers significantly contribute to the care-giving of new-born offspring. However, due to internal fertilization and the nutritional dependence of new-born offspring on lactation, mothers play an essential care-giving role in all mammalian species. Collectively termed "maternal behavior," these care-giving behaviors by a mother have been defined as "responses or behaviors displayed by the female that specifically support the development and growth of her offspring" (1). As such, maternal behavior encompasses complex sets of behaviors that extend beyond the basic 
requirement for shelter and nourishment. The exact compilation of these behaviors and duration of their expression is determined in a species-specific manner. Nonetheless, these sets of behaviors can be broadly classified into either offspring-directed, to refer to direct interactions between mother and offspring, or offspringrelated behaviors, which are not directed at the offspring but are required to ensure safety of young and to support the demands of lactation (1).

To understand the neurobiology underlying maternal mood and behavior in the postpartum period, it is important to note that maternal behavior represents a profound change in a female's behavior. Females in the maternal state will display a different set of behaviors, or perform these behaviors with a different intensity than is observed in non-pregnant females. For example, in many ungulate species, where females remain in close proximity to the herd, a parturient female will isolate herself in order to protect offspring either from the rest of the herd or from predators (2). In rodents, virgin rats will demonstrate maternal behaviors toward foster pups, but this process requires sensitization, involving repeated exposure to pups (3). In contrast, pregnant rats will spontaneously show maternal behavior 2 and $14 \mathrm{~h}$ prior to parturition (4). Although separation of learned vs. inherent maternal responses can be difficult to distinguish in primates, studies in non-human primate species, such as female macaques, have demonstrated that the frequency of infant-directed interactions specifically increases during pregnancy and lactation (5). The onset of enhanced maternal responses being so precisely timed with the birth of offspring, points to an important role for the hormones of pregnancy and lactation in promoting these behaviors. First described in 1972, a humoral basis for maternal behavior (6) has since been the subject of extensive research in a wide variety of mammalian and non-mammalian species. Extensively reviewed elsewhere, multiple hormonal signals contribute to the onset and maintenance of maternal behaviors, including estrogen, progesterone, oxytocin, and prolactin (1, 7-13). Rather than reviewing the role of all these hormones in-depth here, the aim of this review is to provide a focused examination of the literature on the role of the prolactin family of hormones across multiple facets of maternal behavior.

Although prolactin itself has been the focus of many studies, it is but one of a wider group of hormones classed as "lactogenic hormones" that act through a common receptor, the prolactin receptor (Prlr). Lactogenic hormones encompass a group of single peptide hormones of around 200 amino acids that stimulate milk production, and include prolactin, placental lactogens (or chorionic somatomammotropin in women), and in humans, also include growth hormone. In non-pregnant females, circulating prolactin is maintained at low basal levels through a negative feedback loop system. Secretion of placental lactogen or human chorionic somatomammotropin is initiated early in pregnancy with circulating levels increasing until parturition (10). The lactogenic composition during pregnancy is distinct in rodents, with the mating stimulus inducing twice-daily surges in prolactin secretion for the first 9 days of pregnancy (14). However, in the second half of pregnancy, placental lactogen I and II sequentially become the main source of circulating lactogenic hormones present in the blood $(15,16)$. The elevated placental lactogens act via Prlr in the hypothalamus to inhibit maternal prolactin secretion through negative feedback $(17,18)$. This negative feedback regulation disappears in late pregnancy, and suckling induces chronically high levels of prolactin secretion throughout lactation (19). When assessing a potential role for these hormones in influencing maternal behavior, it is important to consider the circulating levels of both placental lactogen (and growth hormone in women) and prolactin during pregnancy and lactation.

Recent studies have suggested that lactogenic hormones may have an important role in regulating postpartum mood in women. Prenatal depression in women is associated with low levels of placental lactogen (20), and postpartum depression has also been linked to low placental lactogen levels at term in mothers who give birth to female infants (21). Potentially one of the primary causes of low placental lactogen production in women is maternal obesity (22), a concurrent risk factor for developing postpartum depression and anxiety (23-25). This finding has been replicated in animal models, with mouse models of maternal obesity leading to suppressed placental lactogen production (26) and poor maternal behavior (27). Furthermore, in addition to effects on placental hormone production during pregnancy, maternal obesity in women is also associated with low prolactin secretion during lactation $(28,29)$. To date, very few studies have investigated the role of lactogens in regulating maternal mood and behavior in women, and our current understanding is derived from mechanistic studies in animal models. In particular, due to their small size, short reproductive life-cycle, and the development of transgenic tools, rodents have been invaluable in identifying how lactogenic hormones influence maternal behavior. The aim of this review is to incorporate what has been learnt from these animal models about the role of lactogenic hormones in both offspring-directed and offspring-related maternal behaviors, and to consider how this might impact on mood in women.

\section{LACTOGENIC SIGNALING IN THE BRAIN}

The Prlr is expressed by a wide range of tissues throughout the body and also in the brain (30-33). At $23 \mathrm{kDa}$ in size, lactogens are too large to cross the blood-brain barrier to exert central actions in the absence of a transporter. Peripherallyderived prolactin enters the brain through a saturable carriermediated transport system $(34,35)$, with levels of prolactin in the cerebrospinal fluid paralleling changes in peripherally circulating prolactin $(36,37)$. While initially thought to be dependent on Prlr expression within the choroid plexus of the brain's ventricular system, recent studies have demonstrated that prolactin transport does not rely on the Prlr, but rather on a currently unidentified transport molecule (35). In addition to peripherally-derived lactogens acting in the brain, recent data also suggests that prolactin itself can be synthesized and released into the cerebrospinal fluid by epithelial cells in the choroid plexus (38). 


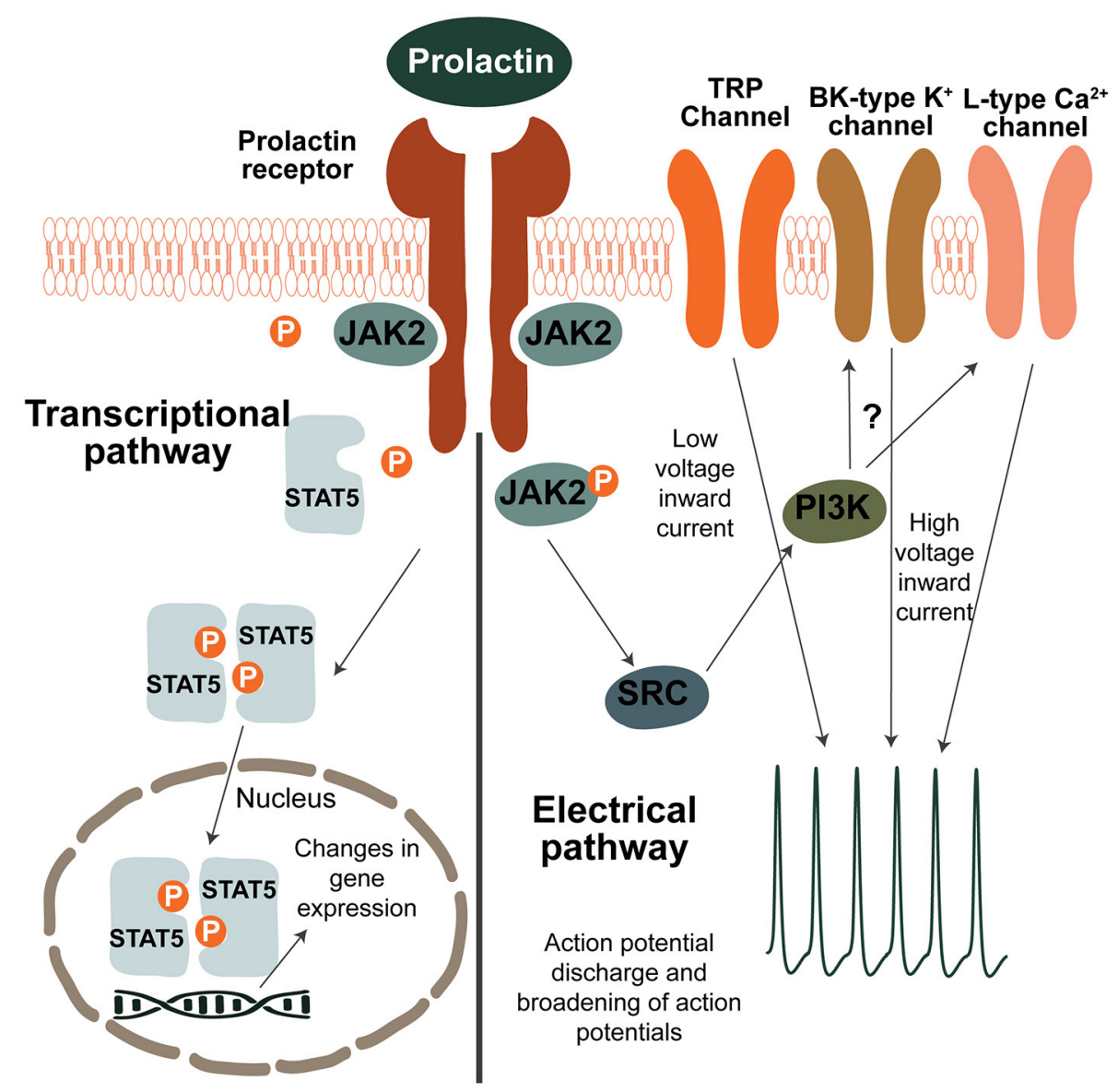

FIGURE 1 | Prolactin-induced signaling pathways in neurons. Transcriptional pathway: binding of prolactin to the prolactin receptor (Prlr) results in activation of JAK2 which in turn phosphorylates several tyroside residues on the Prlr. This causes binding and phosphorylation of STAT5 which then dissociates from the receptor. Two pSTAT5 molecules dimerise and translocate to the nucleus where they lead to changes in gene expression by binging to the promoters of target genes. To induce changes in electrical activity, prolactin activates a low voltage and a high voltage current. The low voltage component is dependent on TRP channels. The high voltage component requires BK-type $\mathrm{K}^{+}$and L-type $\mathrm{Ca}^{2+}$ channels and is dependent on activation of PI3K, however the precise mechanism is unknown. It should be noted that although possible pathways of prolactin-induced signaling are illustrated here, prolactin preferentially acts through the different pathways in a cell-specific and reproductive-state specific manner.

The Prlr is part of the class 1 cytokine receptor superfamily and is composed of the prolactin-binding extracellular domain, a 24 amino acid long transmembrane domain and of the intracellular domain (39). The receptor does not have intrinsic tyrosine kinase activity but is associated with the Janus kinase 2 (JAK2) kinase $(39,40)$. As shown in Figure 1, prolactin binding to the extracellular domain results in dimerization of the receptor and activation of JAK2 which in turn triggers a signaling cascade resulting in phosphorylation and translocation of signal transducer and activator of transcription 5 (pSTAT5) to the nucleus where it exerts targeted effects on gene transcription (39). There are two homologous isoforms of STAT5; STAT5a and STAT5b $(11,17)$, which are often co-expressed in tissues (10). Although in some tissues, such as the mammary gland, STAT5a predominantly mediates prolactin receptor signaling $(41,42)$, in the hypothalamus of the brain, where the Prlr is highly expressed, STAT5b is critical for prolactin action $(43,44)$. To detect prolactin-induced activation in the brain, immunostaining for pSTAT5 can detect phosphorylation of both STAT5 isoforms and has been frequently-used to demonstrate prolactin-induced activity in multiple brain regions, including those known to regulate maternal behaviors (45-50).

Apart from its transcriptional effects, prolactin has also been shown to directly influence neuronal activity (Figure 1). The most pronounced effects have been determined within the short-loop feedback regulation of prolactin secretion. Prolactin acts to stimulate the activity of tuberoinfundibular dopamine (TIDA) neurons in the arcuate nucleus of the hypothalamus (ARN), increasing release of dopamine that subsequently inhibits prolactin release from the anterior pituitary gland. A high proportion ( $>90 \%$ in rats and $\sim 80 \%$ in mice) of TIDA neurons express the Prlr (51-53), and in response to an acute application of prolactin, TIDA neurons switch from their archetypal phasic firing pattern to tonic firing (54). Indeed, prolactin was able to 
increase the activity of a high proportion $(\sim 70 \%)$ of ARN Prlrexpressing cells, as measured by calcium imaging (55). These rapid effects are observed in both males, non-pregnant females and lactating females (54-57). In TIDA neurons, the high voltage component of the prolactin-induced excitation appears to be dependent on the phosphoinositide 3-kinase (PI3K) pathway and requires $\mathrm{BK} \mathrm{K}^{+}$channels, whereas the mixed cationic transient receptor potential (TRP) channels underpin the low voltage component (54). Specifically in females, prolactin also sensitizes TRP channels in sensory neurons and contributes to the regulation of pain responses (58-60). Amongst other brain regions important for maternal behaviors, prolactin has also been shown to have acute effects on neurons in the medial preoptic area (MPOA) $(55,61)$. Compared to the ARN, however, prolactin induces these effects upon a much smaller proportion $(\sim 25 \%)$ of MPOA cells (55), suggesting that prolactin regulates the cells in this brain region primarily through its transcriptional pathways.

The paraventricular nucleus of the hypothalamus (PVN) has also emerged as a brain region controlling maternal behaviors and hosting Prlr-expressing neurons. In this brain region, acute application of prolactin can inhibit a subset of oxytocin neurons in virgin and pregnant rats, but not in lactating rats (6264). Conversely, when specifically examining PVN cells that express the Prlr in the mouse, the acute effects of prolactin are heterogenous, encompassing both inhibitions and excitations in males, virgin females and lactating females (55). However, as with the MPOA, these direct effects on neuronal activity are only seen in a subset of Prlr-expressing PVN neurons ( 30\%) (55), providing evidence that gene transcription is likely to be the primary method of prolactin-induced effects in the PVN. Currently, little is known about the precise mechanism driving prolactin's rapid effects, highlighting the need for further study on this topic.

\section{OFFSPRING-DIRECTED BEHAVIORS (RETRIEVAL, LICKING, NURSING, AND GROOMING)}

Offspring-directed behaviors promote the well-being of young and include all maternal behaviors that involve direct interactions between a mother and offspring. In rodents, this includes retrieval of offspring, licking and grooming, and nursing/crouching behavior. The first investigation into prolactin's role in this maternal behavior was reported in 1935, where repeated exogenous prolactin administration induced maternal behavior in virgin female rats (65). Subsequent experiments showed that the known pro-maternal hormones, estradiol and progesterone, were insufficient on their own to induce maternal behavior in virgin rats, and highlighted the requirement for pituitary-derived prolactin for this behavior to be elicited (66). Since then, research has sought to understand the types of maternal behavior that lactogenic hormones influence, their site of action, and to identify when during pregnancy and lactation these hormones are important (Table 1 and Figure 2).

The generation of a Prlr knockout mouse enabled a more thorough assessment of prolactin's role in offspring-directed maternal behavior. In the absence of all Prlr signaling, pup retrieval and crouching over the pups was severely disrupted in knockout virgin female mice and heterozygote dams (70). Maternal behavior could not be assessed in the homozygote knockout dams in these studies since prolactin action in the ovary is required for the maintenance of pregnancy in rodents $(87,88)$. Confirming the brain as the mediator of these effects, central administration of prolactin induced dosedependent pup retrieval behavior in virgin female rats at doses ineffective when administered peripherally (67). The MPOA of the hypothalamus was identified as a key site in mediating prolactin's role in regulating maternal behavior, with direct infusion of either prolactin or placental lactogen into the MPOA, inducing maternal behavior in non-pregnant rats at a lower dose than required when administered into the lateral ventricles $(67,68)$. Similarly, MPOA infusion of a Prlr antagonist delayed the display of pup-induced maternal behavior in non-pregnant rats (69). The MPOA is widely acknowledged as the center of the neural network that governs maternal responses (8991). The Prlr is expressed in high levels in the MPOA (32, 45,92 ), and exogenously administered prolactin induces high levels of pSTAT5 immunolabeling in non-pregnant mice (45). Indeed, single cell sequencing identified $\sim 70$ different subtypes of neuronal populations in the MPOA, with the Prlr expressed in a large proportion of these, suggesting prolactin may have a broad role in regulating the MPOA (93). Consistent with elevated levels of placental lactogen during pregnancy, pSTAT5 immunolabeling is also high during late pregnancy in mice $(46,94)$, and endogenously high circulating prolactin maintains this increased PSTAT5 labeling during lactation in mouse dams (49). While these studies demonstrated that Prlr signaling in the MPOA could influence maternal behavior, it is only recently that conditional knockout studies have revealed that this signaling is essential for normal postpartum maternal behavior. Targeted deletion of the Prlr from the MPOA of adult female mice abolished maternal behavior, with dams abandoning their offspring shortly after parturition (72). Interestingly, conditional deletion of the Prlr (using a Prlr flox mouse) from either glutamatergic neurons (using a VGlut2-Cre mice to target glutamatergic neurons) or GABA neurons (using a VGat-Cre mouse to target GABA neurons) or from both populations failed to have any effect on litter survival or on pup retrieval in the home cage (72). This suggests that the few remaining neurons within this circuit that still express the Prlr (72) are sufficient to enable maternal behavior to be expressed. The MPOA is characterized by a high degree of interconnectivity (95), and conceptually, prolactin signaling on a few cells could be transmitted more broadly throughout the MPOA through this robust network of neurons.

As Prlrs are required for the onset of maternal nursing behavior, important questions can be raised as to the temporal and mechanistic nature of lactogenic activity during pregnancy and lactation. In both rats and mice, pregnancy has been shown to be accompanied by a period of increased neurogenesis (96, 97) which is important for attenuation of the stress response and normal maternal responses in a stressful environment (71). Prolactin secretion during early pregnancy appears to 
TABLE 1 | Evidence for prolactin regulating specific aspects of maternal behavior.

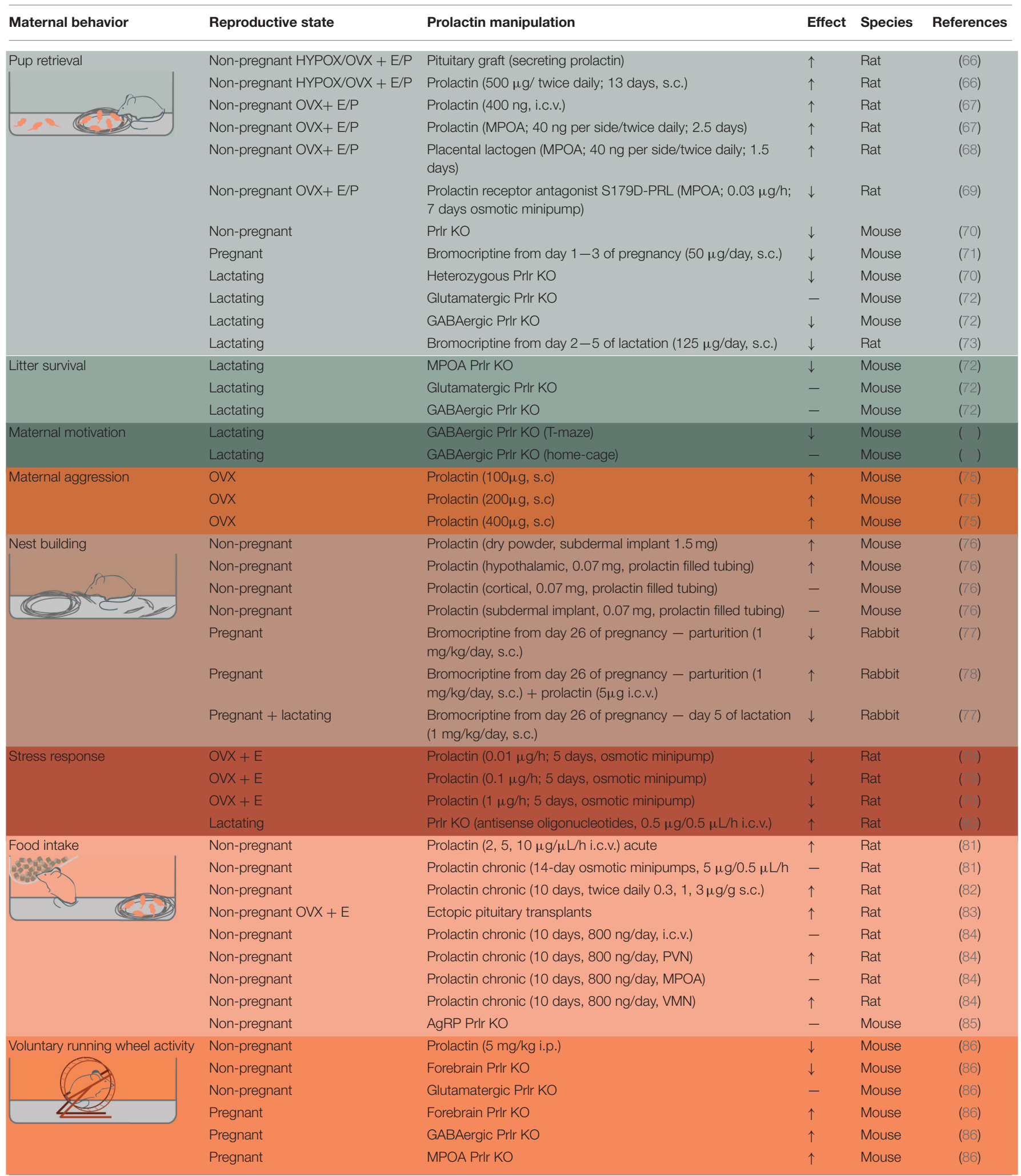

Green shaded rows refer to the role of prolactin on offspring-directed maternal behaviors, while orange shaded boxes describe the role of prolactin on offspring-related behaviors. Upward arrows indicate increase in behavior; downward arrows indicate decrease in behavior; dash represents no change in maternal behavior. E, estrogen; HYPOX, hypophysectomised; i.c.V., intracerebroventricular; i.p., intraperitoneal; $K O$, knockout; MPOA, medial preoptic area; OVX, ovariectomised; P, progesterone; PVN paraventricular nucleus of the hypothalamus; s.c., subcutaneous; VMN, ventromedial nucleus of the hypothalamus. 


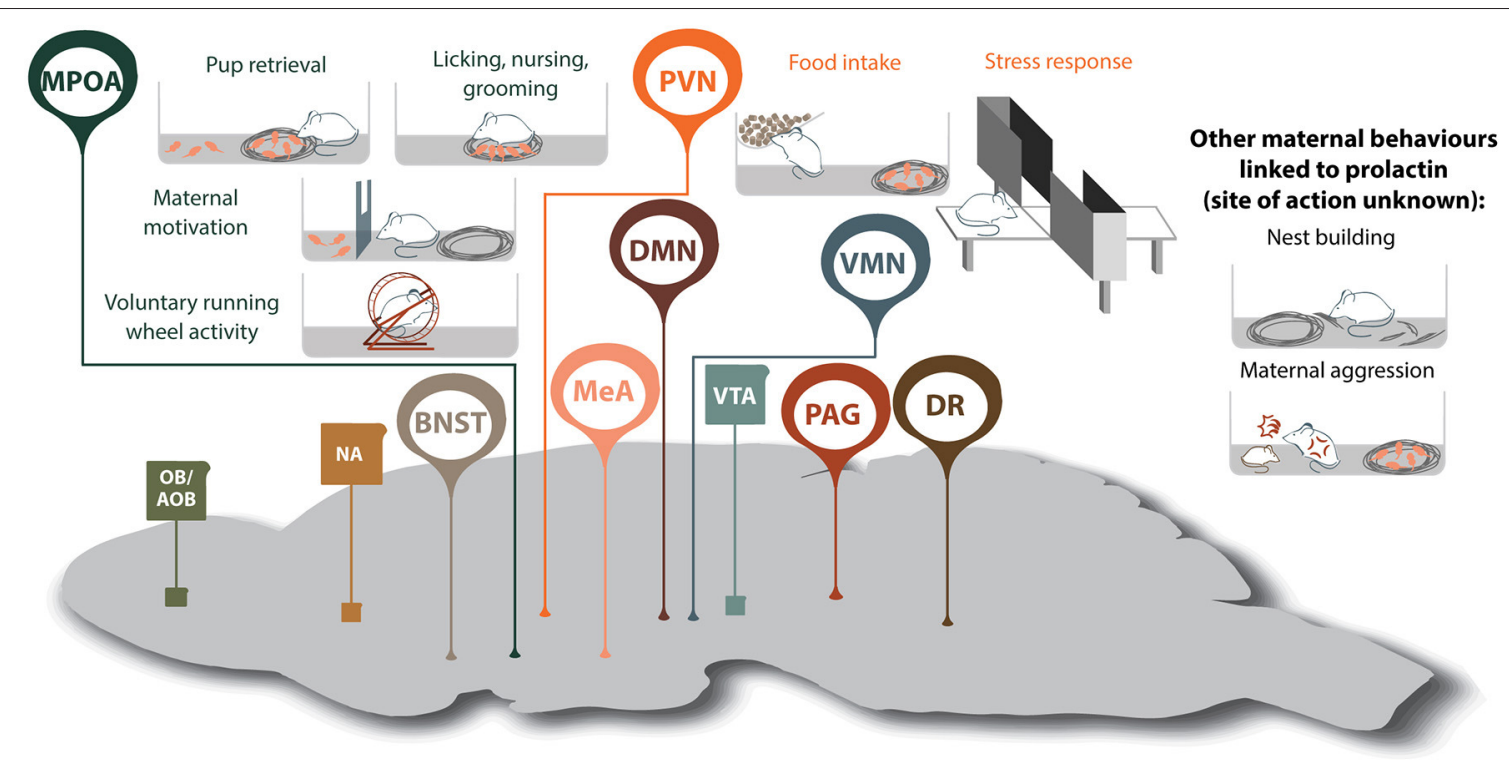

FIGURE 2 | Prolactin-regulated maternal behaviors governed by the maternal neural circuit. Within the neural circuit that regulates maternal behavior, many brain regions show increased prolactin receptor activity during lactation (shown in oval, whereas regions without Prlr but associated with maternal behavior are shown in squares). Note, that although prolactin has been shown to regulate additional aspects of maternal behavior, the brain regions mediating some of these effects are currently unknown. AOB, accessory olfactory bulb; BNST, bed nucleus of the stria terminalis; DMN, dorsomedial nucleus of the hypothalamus; DR, dorsal raphe nucleus; MeA, medial amygdala; MPOA, medial preoptic area; NA, nucleus accumbens; OB, olfactory bulb; PAG, periaqueductal gray; PVN paraventricular nucleus of the hypothalamus; VMN, ventromedial nucleus of the hypothalamus; VTA, ventral tegmental area.

be an important mediator of this increased neurogenesis with reduction of prolactin secretion in early pregnancy, reducing neurogenesis and leading to increased anxiety behavior and poor retrieval behavior of mice in a stressful environment (71). The technical difficulties of manipulating placental lactogen secretion during pregnancy without adversely effecting pregnancy outcomes, represents a substantial challenge in determining the contribution of placental lactogen in regulating maternal behavior.

\section{Maternal Reward and Motivation}

Motherhood is accompanied by high levels of maternal motivation, defined as an increased responsiveness to offspringrelated stimuli and a strong drive to seek out interactions with offspring $(89,98,99)$. This maternal motivation is essential for the sustained expression of maternal behaviors, especially in situations where increased effort is required to provide appropriate care. Various rodent studies have shown that offspring-related stimuli are strongly rewarding to females during lactation, which reinforces their motivation to interact with offspring $(100,101)$. In contrast, the rewarding value of pups and the level of maternal motivation are normally low in nonlactating rat and mouse females $(74,101)$. The rewarding effect of pups is dependent on signaling within the reward system in the brain. Transient inhibition of the ventral tegmental area (VTA) by local administration of bupivacaine disrupts the ability of postpartum rats to form preferences for pupassociated contexts (102). This pup preference is also blocked by bupivacaine-mediated inhibition of the MPOA (103), with neuronal projections linking the MPOA to the VTA, and this pathway specifically driving motivated maternal behaviors such as pup approach and retrieval in mice $(104,105)$.

Studies that specifically focus on the role of lactogenic hormones in maternal motivation have recently started to emerge. A first study reported correlational findings of a link between high maternal motivation in a barrier climbing test and increased Prlr signaling (as measured by pSTAT5 immunoreactivity) in several brain regions, including the MPOA, $\mathrm{MeA}, \mathrm{PVN}$, and posterior intralaminar thalamic nucleus (PIL) (47). Increased pSTAT5 immunoreactivity was also found in the MPOA and PIL of pup-experienced virgins that showed increased maternal motivation in this test (47). Recently we have shown a causal relationship between lactogenic action in the brain and maternal motivation. Lactating mice with a conditional deletion of Prlr from GABAergic neurons (using a VGat-Cre mouse to target GABA neurons) showed impaired pup retrieval behavior in a novel T-maze test, without changes in general anxiety levels. Interestingly, maternal motivation of these females was not impaired in a barrier climbing test, indicating that lactogenic action on GABA neurons is necessary for full maternal motivation under specific conditions (74). Given the importance of the MPOA-VTA circuit in directing maternal motivation and the presence of a prolactin-sensitive MPOA-VTA projection (72), prolactin could be acting directly on GABAergic neurons in the MPOA to alter maternal motivation.

Identifying the neural circuits and hormonal factors that promote offspring-directed behaviors in mothers has important implications for the regulation of postpartum mood in women. 
Postpartum depression affects numerous maternal caregiving behaviors and is accompanied by an increased risk for poor mother-baby attachment $(106,107)$. Neural imaging studies in postpartum women have shown activation of reward regions of the brain, including the VTA, when women view images of their own infants smiling faces (108-110). In contrast, women with postpartum depression show reduced responses to viewing their own infant's smiling faces, and to hearing their own infant cry (111-113). With an accumulating evidence base for an important role for lactogenic hormones in promoting mother-infant interactions, future investigation into the correlation between impaired lactogenic signaling (to encompass all lactogenic hormones) and the occurrence of postpartum mood disorders in women is warranted.

\section{OFFSPRING-DIRECTED BEHAVIORS}

\section{Maternal Aggression}

Maternal aggression is typically exhibited by postpartum females, but not by non-pregnant females, and allows a mother to guard her young from dangers and perceived threats. Lactating females will therefore engage in both offensive and defensive behaviors toward an unfamiliar intruder (114). This maternal adaptation is an evolutionarily-conserved trait that is broadly exhibited by many different species, both in domestic animals and in the wild and includes rodents, non-human primates and humans (115-122). The specific expression of this aggressive behavior during early lactation occurs at a time when the levels of prolactin are high, suggesting prolactin might be involved in regulating this behavior. Interestingly, in humans, the level of postpartum aggression is higher in women who are breast-feeding compared to formula feeders and nulliparous females (122). Furthermore, lactating or nonpregnant women with hyperprolactinemia (chronically elevated prolactin) display similar levels of heightened hostility compared to control non-pregnant women (123). These experiments assessed aggression using a Kellner Symptom Questionnaire, which provided values of anxiety, depression, somatic symptoms, and hostility (123). Depression and anxiety scores were higher in hyperprolactinaemic patients than postpartum women and controls, yet the hostility levels were similar between the former two groups (123). A more recent study utilized the 90-item symptom checklist to examine similar parameters in hyperprolactinaemic patients (124). In contrast to earlier studies, anxiety and depression parameters were not different between control group and hyperprolactinaemic patients (124). However, hostility levels were higher in hyperprolactinaemic patients (124), again indicating that prolactin might play in role in regulating aggressive behaviors. It is important to note that a vast majority of these studies examined subjects whose prolactin levels were abnormally high due to a medical condition, thereby not excluding the effects could be attributed to other associated comorbidities.

Animal models have been used to interrogate the neural circuitry underlying aggressive behavior in both males and females, with the medial amygdala $(\mathrm{MeA})$ and ventromedial nucleus of the hypothalamus (VMN) emerging as key regulatory sites $(125,126)$. An initial indication that prolactin might be involved in maternal aggression came from a study carried out on golden hamsters (118). The level of aggression displayed by these animals was highest during pregnancy and lactation, and lowest during pseudopregnancy (development of signs of pregnancy without the presence of an implanted embryo) and estrous (118), matching the patterns of blood prolactin levels in this species. In ovariectomized white-footed mice (Peromyscus leucopus), prolactin administration increased levels of intruderdirected aggression in a dose-dependent manner (75). At the higher prolactin doses ( $>200 \mathrm{ug}$ ), levels of aggression were similar between prolactin-injected ovariectomised mice and lactating females (75). Surprisingly, drastically reducing prolactin levels through hypophysectomy (removal of the pituitary gland), did not affect aggression in parturient Rockland-swiss mice (127). However, this approach would not suppress Prlr signaling during pregnancy, as placental lactogen secretion (the primary ligand for the Prlr during pregnancy) would not be affected by hypophysectomy. Interestingly, Prlr signaling in both the MeA and $\mathrm{VMN}$ is increased in during pregnancy and lactation (49, 94), suggesting lactogenic action in these regions may modulate maternal aggression at these times.

In humans, maternal aggression is an important component of postpartum mood, and disturbances in the regulation of this adaptation can lead to heightened anger toward self, the child or other family members (128). The likelihood of displaying abnormal levels of anger is also associated with postpartum depression and lower emotional availability for their children (128). Similarly, elevated postpartum anxiety is linked with abnormally high levels of intruder-directed maternal aggression (129), an indicator of hypervigilant parenting. Understanding how maternal protective behaviors are controlled in a healthy pregnancy and lactation is therefore key for developing effective strategies to promote development of healthy motherchild interactions.

\section{Nest Building}

An important component of maternal behavior, particularly in altricial species, is maternal nest building. This energeticallycostly process ensures offspring survivability as the young from these species have limited capacity for thermoregulation and locomotion. As with other maternal behaviors, nest building is highly conserved between species.

Female mice can construct either a sleeping nest or a brood nest, the latter being considered the maternal nest (130). The brood nest is significantly larger and encloses the animals so that they cannot be easily seen while in the nest. Mice begin to build the brood nest during early gestation, with this behavior enhanced by exposure to pups and able to be blocked by olfactory bulb removal $(130,131)$. Pseudopregnant mice also build maternal nests compared to virgin controls, suggesting a hormonal basis for the regulation of this behavior (132). Evidence of prolactin's involvement in maternal nest building came from early studies administering prolactin to virgin mice (76). Virgin female mice that received either hypothalamic or subdermal implants of prolactin built superior nests than control mice or mice with cortical-implants of prolactin (76). Manipulation of 
prolactin levels in rabbits are also able to alter maternal nest building $(77,78)$. For example, blocking prolactin secretion from day 26 of pregnancy until parturition via sub-cutaneous bromocriptine injections significantly reduced the construction of maternal nests in rabbits (77). This deficit in maternal nest building was rescued in rabbits receiving intracerebroventricular (i.c.v.) prolactin, suggesting a direct role of this hormone in the execution of this behavior $(78,133)$. Several studies have indicated that MPOA neurons drive nest building (134, 135), and with Prlr expression in this brain region regulating other maternal behaviors (72), the MPOA could conceptually also mediate the effects of prolactin on nest building.

The equivalent of nesting behaviors in human mothers, may be preparation of the physical environment and social selectivity, both of which peak in the third trimester of pregnancy (136). Interestingly, this corresponds with peak secretion of placental lactogen, and suggests the lactogenic hormones may have a causal role in this behavior. However, further studies are required to determine the precise mechanism underlying hormonal regulation of nest building behavior, and whether it may be relevant to understanding forms of maternal neglect in humans.

\section{Attenuated Stress Response}

During pregnancy and lactation, the reactivity of the hypothalamic-pituitary-adrenal (HPA) axis of multiple species, including humans, is drastically reduced (137, 138). Stress during pregnancy and lactation can detrimentally impact pregnancy outcomes, increasing the likelihood that the mother will abandon her pups and the prevalence of postpartum mood disorders (139-141). Gestational stress also has negative effects on fetal development and contributes to programming hyperactive stress responses in the offspring (140, 142-144). Reduced HPA axis reactivity is therefore a critical adaptation that serves to protect both the mother and offspring from these stress-related effects. In mice, suppression of the stress response during lactation is evident both following a restraint or endotoxin stressors, with attenuated adrenocorticotropic hormone $(\mathrm{ACTH})$ and corticosterone secretion compared to virgin females (145). Similarly, in humans, temperature or exercise-induced stressors are dampened during pregnancy and lactation, respectively $(137,146)$.

As a potential regulator of these changes, prolactin has been shown to have dose-dependent anxiolytic effects in nonpregnant rats $(79,147)$. Chronic administration of prolactin for 5 days in virgin rats reduces $\mathrm{ACTH}$ and corticosterone secretion following a restraint or anxiety-like stressor (79). Interestingly, following exposure to the stressor, prolactin-injected animals showed reduced c-fos immunoreactivity (a marker of neuronal activation) in the PVN (79), a key region controlling the stress response, hinting at a mechanism by which prolactin exerts its anxiolytic effects. The PVN is host to corticotropin-releasing hormone $(\mathrm{CRH})$ neurons, a population proven to regulate a plethora of physiological and behavioral stress-related responses (148-150). Evidence from earlier studies suggested prolactin can regulate the activity of $\mathrm{CRH}$ neurons in hypothalamic explants (151). More recently, studies in mice have demonstrated that PVN Crh mRNA levels are lower during pregnancy and lactation compared to the virgin controls (152). Pup-removal, and thereby blocking suckling-induced prolactin secretion, lead to an increase in PVN Crh mRNA and this was restored to the low lactating levels following prolactin administration for $24 \mathrm{~h}$ in mice (152). However, these effects do not appear to be direct as Prlr mRNA is not expressed by PVN CRH neurons (153). Similarly, both in virgin and lactating mice and rats, prolactin does not directly activate PVN CRH neurons (as measured by pSTAT5 immunoreactivity) (153). Nonetheless, downregulation of Prlr in the brain resulted in increased anxiety-related behaviors and higher ACTH secretion in lactating rats (80). Thus, while the precise brain region where prolactin acts to exert its anxiolytic effects is not yet known, it is evident this pituitary hormone plays an important role in regulating this maternal adaption.

In women, increased anxiety and stress during pregnancy are risk factors for preterm birth and low birth weight while also negatively impacting mother-child interactions (154-156). Similarly, the high prevalence rates of perinatal anxiety in women $(157,158)$ highlights the importance of understanding how stress is regulated during pregnancy, particularly since these early life interactions are critically important in child development.

\section{Metabolic Adaptations}

Profound changes in metabolic regulation are essential to provide sufficient energy for the development of the growing fetus and to meet the high metabolic demands of lactation. From a behavioral perspective, this involves changes to both food intake and voluntary energy expenditure. Food intake drastically increases during pregnancy and lactation in humans and other mammalian species (159-163). Interestingly, lower body weight increase during pregnancy is associated with litter loss and overall poor pregnancy outcomes (164). Research on the neuronal pathways regulating food intake and energy balance has largely focused on the medial basal hypothalamus, with the ARN considered to be the center of the neural circuit regulating food intake. This brain structure is host to two key neuronal populations known to affect energy balance; the adjacent yet functionally antagonistic, proopiomelanocortin (POMC) and agouti-related peptide/neuropeptide Y (AgRP/NPY) neurons that exert powerful effects on satiety and hunger, respectively (165-167). In order to exert effects on feeding behavior, some of the important hypothalamic projection regions of these ARN neuronal populations include the PVN, dorsomedial hypothalamus, ventromedial hypothalamus and lateral hypothalamus (168-170).

Multiple studies have linked prolactin action with food intake and body weight in non-pregnant rats (summarized in Table 1) (81-83). Prolactin appears to act at the level of the PVN to influence appetite, with chronic prolactin administration in this brain region increasing food intake (84). In the pregnant state, rodents eat more and become insensitive to the effects of the satiety hormone, leptin, particularly in the hypothalamic regions associated with leptin's effects on food intake (159, 171). This leptin resistance appears to be driven by placental lactogen secretion in the second half of pregnancy, with prolactin administration to pseudopregnant rats blocking the satiety effects 
of leptin (172). During lactation, increased food intake is necessary to meet the high energy demand of milk production. This hyperphagia appears to be dependent on increases in the orexigenic AgRP and NPY, and a decrease in POMC expression (173-175). There is evidence suggesting prolactin plays a role in regulating the hyperphagia of lactation, but not through direct actions on POMC or AgRP neurons in the ARN (85, 176). A population of NPY neurons in the DMN are also important for regulating energy metabolism and food intake (177, 178), with many of these showing increased prolactin receptor activity during lactation compared to the non-pregnant state $(33,49,179)$. Expression of NPY mRNA in the DMN increases during lactation and blocking prolactin secretion (via bromocriptine administration) abrogates this effect (179), suggesting that prolactin stimulates production of orexigenic NPY during lactation. To further evaluate the precise role of DMN Prlr-expressing cells in mediating lactational increase in food intake, future studies would be required to precisely knockout Prlr in this brain region.

In order to adapt to the huge energy demands of pregnancy and lactation, changes in voluntary activity accompany increased food intake. Even from very early in pregnancy, rodents conserve energy by reducing voluntary running wheel activity (164). Interestingly, one study has shown that this reduction in running behavior can predict lactation success in mice (164). Mouse dams who abandoned their litters showed greater running wheel activity and lower weight gain during pregnancy compared to the pregnancies of dams who successfully reared their litters (164). Recent data suggests Prlr activity plays an important role in regulating this voluntary running behavior. In non-pregnant females but not males, peripheral prolactin administration can acutely reduce running wheel activity without affecting general locomotion (86). Furthermore, forebrain-specific knockout of Prlrs (using a Cam kinase II Cre mouse to target forebrain neurons) blocks the pregnancy-induced decrease in running wheel activity, with the MPOA and GABA neurons likely to be mediating these effects of prolactin (86).

The reduction in physical activity during pregnancy is also apparent in human mothers (180). Despite positive attitudes toward physical exercise, there is a significant decrease in physical activity engagement during pregnancy (180). Since increased weight gain during pregnancy is associated with heighted risk of complications and lower delivery outcomes (181), understanding maternal metabolic adaptions is imperative. Although the rodent studies have provided evidence for lactogenic hormones playing an important role in regulating maternal metabolic adaptations, the precise mechanisms mediating these effects are currently unknown, and warrant further investigation.

\section{TRANSGENERATIONAL EFFECTS}

A growing field of research has demonstrated behavioral transmission of postpartum behavior from mothers to female offspring. Most commonly, this has been used to investigate the effect of stress on subsequent offspring's maternal behavior. In these studies, female rat pups that were separated from their mothers for either short or long periods of time, went on to exhibit impaired maternal behavior with their own offspring $(182,183)$. In addition to direct effects on maternal behavior, prolactin appears to have a transgenerational effect on maternal behavior. Reducing prolactin content of milk in lactating rat dams decreases maternal responses to foster pups in the virgin adult female offspring (73). Mice with a deletion of the Cbl-interacting protein of $85 \mathrm{kDa}$ (Cin85) were able to nurture and raise pups, however, when producing their own pups, these $F_{1}$ offspring were found to have severely disrupted maternal care (184). Examination of prolactin secretion in the first generation of Cin85-deleted mice, showed greatly reduced prolactin production during late pregnancy and early lactation, and prolactin administration to these mice during pregnancy was able to rescue the subsequent offspring maternal behavior (184). This indicates that the in utero prolactin environment can alter maternal behavior of offspring through non-genomic transmission. Studies looking at transgenerational effects of high and low licking and grooming rat mothers, have found changes in the methylation of the estrogen receptor alpha promoter in the MPOA, which may alter estrogen sensitivity in this region and account for altered maternal responses of offspring (185). Although the mechanism underlying a transgenerational effect of prolactin is unknown, it could involve a similar epigenetic mechanism to alter sensitivity to prolactin in key brain regions that regulate maternal behavior.

\section{LACTOGENIC HORMONES AMONGST THE CHANGING HORMONAL PROFILE OF PREGNANCY AND LACTATION}

Although this review focuses on the role of lactogenic hormones on the multiple facets of maternal behavior, it is important to note that multiple hormones and factors influence maternal behavior. Indeed, lactogenic hormones are not acting in isolation, and there is considerable overlap and interactions between these regulators of maternal behavior. Briefly discussed here are some of the key hormonal regulators of maternal behavior that are known to interact with lactogenic hormones.

One significant convergence point for some of these factors is the interaction with TIDA neurons in the ARN, where stimulation (e.g., by thyrotropin-releasing hormone, orexin, oxytocin) or suppression (e.g., by serotonin/5-HT, estrogen, enkephalin, dynorphin) of TIDA neuronal activity, can alter secretion of prolactin from the anterior pituitary $(19,186-$ 193), and therefore has the potential to also indirectly influence maternal behavior. For example orexin inhibits the activity of ARN TIDA neurons resulting in increased prolactin secretion, and is known to alter maternal behavior in a dose dependent manner $(194,195)$. In postpartum mice, high i.c.v. doses $(0.3$ $\mu \mathrm{g}$ ) of orexin worsened pup retrieval and decreased nursing and nesting behavior, whereas at lower doses $(0.06-0.1 \mu \mathrm{g})$, orexin mildly improved pup licking and grooming (194). The MPOA appears to mediate some of these effects with MPOA administration of a orexin receptor antagonist increasing pup nursing time in rat dams (196). However, given the effect of 
orexin in TIDA neuronal activity, it is possible orexin could also indirectly be influencing maternal behavior through modulating prolactin secretion.

Serotonin (5-HT) is also known to promote prolactin release $(188,197)$, and 5-HT neurons can regulate maternal behavior. Deletion of 5-HT neurons from the brain impairs behaviors such as pup retrieval, nest building, and nursing, without affecting maternal protective behaviors (198). Specifically, 5-HT neurons located in the largest raphe nuclei, the dorsal raphe, are important for pup retrieval and survival (199). This was also associated with reduced pup milk intake, suggesting reduced prolactin inhibitory tone (199). Interestingly, evidence from an earlier study could provide a mechanistic explanation for this phenomenon as dorsal and median raphe lesions reduced suckling-induced prolactin release (200). Due to the wide use of selective serotonin reuptake inhibitors to treat maternal mood disorders, it is important to consider the changes of 5-HT during the postpartum period and how these impact maternal behaviors (201).

The role of oxytocin in stimulating maternal behavior has been the subject of much research. Acting as a neurotransmitter, oxytocin is also released centrally by neurons in the PVN and supraoptic (SON) nuclei and can alter social and maternal behaviors. Central oxytocin administration to ovariectomised and estrogen primed rats can induce maternal behaviors such as grooming, nest building and pup retrieval (202). In particular, retrieval in response to pup calls is dependent on oxytocin receptors expressed by left auditory cortex neurons (203). Oxytocin is also known to influence maternal aggression in postpartum females (114) and in homozygous oxytocin knockout mice, the duration of time spent attacking the intruder was significantly reduced (204). In rats, Prlrs are expressed on oxytocin neurons, and in virgin and pregnant rats, i.c.v prolactin administration inhibits the activity of these neurons (62-64, 205). Interestingly this inhibition is lost during lactation (63), potentially enabling both these pro-maternal factors to be released at higher levels.

The establishment of sex steroids playing a key role in regulating maternal behavior dates back to the 1970 's, whereby nulliparous ovariectomised females treated with estrogen retrieved pups significantly faster than the control rats $(1,206)$. The MPOA again emerged as the brain region important for mediating estrogen's effects on pup retrieval, with knockdown of MPOA estrogen receptor $\alpha$ $(\mathrm{ER} \alpha)$ expression leading to decreased pup nursing, licking, and retrieval (207). Estrogen could also indirectly promote maternal behavior through regulating lactogenic hormone signaling, with estrogen treatment upregulating Prlr mRNA expression in the brain $(208,209)$. Progesterone has emerged as a negative regulator of maternal behavior and primarily influences maternal behavior through modulating the actions of other hormones (210). In ovariectomised, nulliparous rats, chronic progesterone administration suppressed Prlr mRNA expression in the MPOA (211). Progesterone withdrawal as seen in rodents and functional withdrawal of progesterone as seen in women at the end of pregnancy (212), may thus contribute to facilitating the stimulation of maternal behavior by lactogenic hormones.

\section{CONCLUSIONS AND FUTURE DIRECTIONS}

Motherhood is a period of dramatic physiological and behavioral change that ultimately ensures healthy development of offspring. While some studies have studied the mechanisms driving maternal behaviors in humans, rodent models have proven invaluable in deciphering how these adaptations are achieved. In both humans and rodents, lactogenic hormones are elevated during pregnancy and lactation, and by acting on the widelydistributed Prlr, regulate multiple behavioral functions (10, 213). Amongst these, we have highlighted that these lactogenic hormones exert profound effects on a diverse range of both young-directed and young-related maternal behaviors. There is substantial evidence that Prlr signaling is important for offspringdirected behaviors including pup retrieval, licking nursing, grooming and on increasing maternal motivation, as well as offspring-related behaviors such as reducing anxiety, building a nest and maternal aggression (Figure 2). For these behaviors, prolactin actions have been linked, at least in part, through actions on the MPOA and PVN. Interestingly, Prlr signaling is also increased in multiple additional regions of the maternal brain that are known to be important for governing aspects of maternal behavior, such as the MeA, and yet, the role of prolactin in these regions is unclear (Figure 2). With such broad implication for regulating mood and behavior in mother, there is clearly a need to more precisely understand the neuronal circuits that govern these prolactin-driven maternal adaptations.

Alongside this period of extensive maternal adaptation in pregnancy and lactation, is also an increased risk of developing mood disorders. Maternal mood disorders represent a significant health burden worldwide with $\sim 20 \%$ of women suffering either from postpartum depression or postpartum anxiety. Maternal mental health problems during pregnancy and the postpartum period represent a significant barrier in developing healthy mother-infant interactions. Treatment for postpartum mood disorders often relies on either psychological intervention such as cognitive behavioral therapy or pharmacological intervention including antidepressants or hormone therapy. However, until we have a better understanding of the physiological processes that lead to both normal and abnormal adaptations to pregnancy, and the molecular mechanisms that underlie these processes, our ability to develop new therapies to treat impaired adaptations during pregnancy and early lactation are limited.

\section{AUTHOR CONTRIBUTIONS}

TG, JS, and RB wrote the manuscript. TG created the figures. TG, $\mathrm{DG}$, and RB edited the manuscript. All authors contributed to the article and approved the submitted version.

\section{FUNDING}

This work was supported by a Health Research Council of New Zealand Project Grant and conducted during tenure of the Sir Charles Hercus Health Research Fellowship (by RB) of the Health Research Council of New Zealand. 


\section{REFERENCES}

1. Bridges RS. Neuroendocrine regulation of maternal behavior. Front Neuroendocrinol. (2015) 36:178-96. doi: 10.1016/j.yfrne.2014.11.007

2. Rørvang MV, Nielsen BL, Herskin MS, Jensen MB. Prepartum maternal behavior of domesticated cattle: A comparison with managed, feral, and wild ungulates. Front Vet Sci. (2018) 5:45. doi: 10.3389/fvets.2018.00045

3. Rosenblatt JS. Nonhormonal basis of maternal behavior in the rat. Science. (1967) 156:1512-4. doi: 10.1126/science.156.3781.1512

4. Slotnick BM, Carpenter ML, Fusco R. Initiation of maternal behavior in pregnant nulliparous rats. Horm Behav. (1973) 4:53-9. doi: 10.1016/0018-506X(73)90016-0

5. Maestripieri D, Wallen $\mathrm{K}$. Interest in infants varies with reproductive condition in group-living female pigtail macaques (Macaca nemestrina). Physiol Behav. (1995) 57:353-8. doi: 10.1016/0031-9384(94)00222-Q

6. Terkel J, Rosenblatt JS. Humoral factors underlying maternal behavior at parturition: corss transfusion between freely moving rats. J Comp Physiol Psychol. (1972) 80:365-71. doi: 10.1037/h0032965

7. Kendrick KM. Oxytocin, motherhood and bonding. Exp Physiol. (2000) 85:111S-24. doi: 10.1111/j.1469-445X.2000.tb00014.x

8. Pedersen CA. Oxytocin control of maternal behavior. Ann N Y Acad Sci. (1997) 807:126-45. doi: 10.1111/j.1749-6632.1997.tb51916.x

9. Stolzenberg DS, Champagne FA. Hormonal and non-hormonal bases of maternal behavior: The role of experience and epigenetic mechanisms. Horm Behav. (2016) 77:204-10. doi: 10.1016/j.yhbeh.2015.07.005

10. Smiley KO, Ladyman SR, Gustafson P, Grattan DR, Brown RSE. Neuroendocrinology and adaptive physiology of maternal care BT neuroendocrine regulation of behavior. In: Coolen LM, Grattan DR, editors. Cham: Springer International Publishing (2019). p. 161-210. doi: 10.1007/7854_2019_122

11. Fleming AS, Kraemer GW. Molecular and genetic bases of mammalian maternal behavior. Gend Genome. (2019) 3:247028971982730. doi: $10.1177 / 2470289719827306$

12. Kuroda KO, Tachikawa K, Yoshida S, Tsuneoka Y, Numan M. Neuromolecular basis of parental behavior in laboratory mice and rats: With special emphasis on technical issues of using mouse genetics. Prog Neuro-Psychopharmacol Biol Psychiatry. (2011) 35:1205-31. doi: 10.1016/j.pnpbp.2011.02.008

13. Yoshihara C, Numan M, Kuroda KO. Oxytocin and parental behaviors. In: Hurlemann R, Grinevich V, editors. Behavioral Pharmacology of Neuropeptides: Oxytocin. Cham: Springer International Publishing (2018). p. 119-53. doi: 10.1007/7854_2017_11

14. Barkley MS, Bradford GE, Geschwind II. The pattern of plasma prolactin concentration during the first half of mouse gestation. Biol Reprod. (1978) 19:291-6. doi: 10.1095/biolreprod19.2.291

15. Robertson MC, Friesen HG. Two forms of rat placental lactogen revealed by radioimmunoassay. Endocrinology. (1981) 108:2388-90. doi: 10.1210/endo-108-6-2388

16. Robertson MC, Gillespie B, Friesen HG. Characterization of the two forms of rat placental lactogen (rPL): rPL-I and rPL-II. Endocrinology. (1982) 111:1862-6. doi: 10.1210/endo-111-6-1862

17. Tonkowicz PA, Voogt JL. Termination of prolactin surges with development of placental lactogen secretion in the pregnant rat. Endocrinology. (1983) 113:1314-8. doi: 10.1210/endo-113-4-1314

18. Lee Y, Voogt JL. Feedback effects of placental lactogens on prolactin levels and fos-related antigen immunoreactivity of tuberoinfundibular dopaminergic neurons in the arcuate nucleus during pregnancy in the rat. Endocrinology. (1999) 140:2159-66. doi: 10.1210/endo.140.5.6730

19. Yip SH, Romanò N, Gustafson P, Hodson DJ, Williams EJ, Kokay IC, et al. Elevated prolactin during pregnancy drives a phenotypic switch in mouse hypothalamic dopaminergic neurons. Cell Rep. (2019) 26:1787-99.e5. doi: 10.1016/j.celrep.2019.01.067

20. Janssen AB, Capron LE, O’Donnell K, Tunster SJ, Ramchandani PG, Heazell $\mathrm{AEP}$, et al. Maternal prenatal depression is associated with decreased placental expression of the imprinted gene PEG3. Psychol Med. (2016) 46:2999-3011. doi: 10.1017/S0033291716001598

21. Sumption LA, Garay SM, John RM. Low serum placental lactogen at term is associated with postnatal symptoms of depression and anxiety in women delivering female infants. Psychoneuroendocrinology. (2020) 116:104655. doi: 10.1016/j.psyneuen.2020.104655

22. Jin Y, Vakili H, Liu SY, Menticoglou S, Bock ME, Cattini PA. Chromomal architecture and placental expression of the human growth hormone gene family are targeted by pre-pregnancy maternal obesity. Am J Physiol Endocrinol Metab. (2018) 315:E435-45. doi: 10.1152/ajpendo.00042.2018

23. Steinig J, Nagl M, Linde K, Zietlow G, Kersting A. Antenatal and postnatal depression in women with obesity: a systematic review. Arch Womens Ment Health. (2017) 20:569-85. doi: 10.1007/s00737-017-0739-4

24. Jarmasz JS, Anderson A, Bock ME, Jin Y, Cattini PA, Ruth C. A potential role for insulin treatment during pregnancy in reducing postpartum psychological distress in maternal obesity: an administrative population health study. BMC Womens Health. (2021) 21:1-11. doi: 10.1186/s12905-021-01261-0

25. Cattini PA, Jin Y, Jarmasz JS, Noorjahan N, Bock ME. Obesity and regulation of human placental lactogen production in pregnancy. J Neuroendocrinol. (2020) 32:1-8. doi: 10.1111/jne.12859

26. Musial B, Vaughan OR, Fernandez-Twinn DS, Voshol P, Ozanne SE, Fowden AL, et al. A Western-style obesogenic diet alters maternal metabolic physiology with consequences for fetal nutrient acquisition in mice. J Physiol. (2017) 595:4875-92. doi: 10.1113/JP273684

27. Buonfiglio DC, Ramos-Lobo AM, Freitas VM, Zampieri TT, Nagaishi VS, Magalhães $M$, et al. Obesity impairs lactation performance in mice by inducing prolactin resistance. Sci Rep. (2016) 6:1-13. doi: 10.1038/srep22421

28. Rasmussen KM, Kjolhede CL. Prepregnant overweight and obesity diminish the prolactin response to suckling in the first week postpartum. Pediatrics. (2004) 113:e465. doi: 10.1542/peds.113.5.e465

29. Lee S, Kelleher SL. Biological underpinnings of breastfeeding challenges: The role of genetics, diet, and environment on lactation physiology. Am J Physiol - Endocrinol Metab. (2016) 311:E405-22. doi: 10.1152/ajpendo.00495.2015

30. Aoki M, Wartenberg P, Grünewald R, Phillipps HR, Wyatt A, Grattan $\mathrm{DR}$, et al. Widespread cell-specific prolactin receptor expression in multiple murine organs. Endocrinology. (2019) 160:2587-99. doi: 10.1210/en.2019-00234

31. Ouhtit A, Morel G, Kelly PA. Visualization of gene expression of short and long forms of prolactin receptor in the rat. Endocrinology. (1993) 133:135-44. doi: 10.1210/endo.133.1.8319561

32. Bakowska JC, Morrell JI. Atlas of the neurons that express mRNA for the long form of the prolactin receptor in the forebrain of the female rat. J Comp Neurol. (1997) 386:161-77. doi: 10.1002/(SICI)1096-9861(19970922)386:2<161::AID-CNE1>3.0.CO;2-\#

33. Kokay IC, Wyatt A, Phillipps HR, Aoki M, Ectors F, Boehm U, et al. Analysis of prolactin receptor expression in the murine brain using a novel prolactin receptor reporter mouse. J Neuroendocrinol. (2018) 30:1-20. doi: $10.1111 /$ jne. 12634

34. Walsh RJ, Slaby FJ, Posner BI. A receptor-mediated mechanism for the transport of prolactin from blood to cerebrospinal fluid. Endocrinology. (1987) 120:1846-50. doi: 10.1210/endo-120-5-1846

35. Brown RSE, Wyatt AK, Herbison RE, Knowles PJ, Ladyman SR, Binart $\mathrm{N}$, et al. Prolactin transport into mouse brain is independent of prolactin receptor. FASEB J. (2016) 30:1002-10. doi: 10.1096/fj.15-276519

36. Login IS, MacLeod RM. Prolactin in human and rat serum and cerebrospinal fluid. Brain Res. (1977) 132:477-83. doi: 10.1016/0006-8993(77)90196-2

37. Nicholson G, Greeley GH, Humm J, Youngblood WW, Kizer JS. Prolactin in cerebrospinal fluid: a probable site of prolactin autoregulation. Brain Res. (1980) 190:447-57. doi: 10.1016/0006-8993(80)90287-5

38. Costa-Brito AR, Quintela T, Gonçalves I, Duarte AC, Costa AR, Arosa FA, et al. The choroid plexus is an alternative source of prolactin to the rat brain. Mol Neurobiol. (2021) 58:1846-58. doi: 10.1007/s12035-020-0 $2267-9$

39. Bole-Feysot C, Goffin V, Edery M, Binart N, Kelly PA. Prolactin (PRL) and its receptor:Actions, signal transduction pathways and phenotypes observed in PRL receptor knockout mice. Endocr Rev. (1998) 19:225-68. doi: 10.1210/edrv.19.3.0334

40. Finidori J, Kelly PA. Cytokine receptor signaling through two novel families of transducer molecules: Janus kinases, and signal transducers and activators of transcription. J Endocrinol. (1995) 147:11-23. doi: 10.1677/joe.0.14 70011 
41. Hennighausen L, Robinson GW. Interpretation of cytokine signaling through the transcription factors STAT5A and STAT5B. Genes Dev. (2008) 22:711-21. doi: 10.1101/gad.1643908

42. Liu X, Robinson GW, Wagner KU, Garrett L, Wynshaw-Boris A, Hennighausen L. Stat5a is mandatory for adult mammary gland development and lactogenesis. Genes Dev. (1997) 11:179-86. doi: $10.1101 / \operatorname{gad} .11 .2 .179$

43. Yip SH, Eguchi R, Grattan DR, Bunn SJ. Prolactin signalling in the mouse hypothalamus is primarily mediated by signal transducer and activator of transcription factor 5b but not 5a. J Neuroendocrinol. (2012) 24:1484-91. doi: 10.1111/j.1365-2826.2012.02357.x

44. Grattan DR, Xu J, McLachlan MJ, Kokay IC, Bunn SJ, Hovey RC, et al. Feedback regulation of PRL secretion is mediated by the transcription factor, signal transducer, and activator of transcription 5b. Endocrinology. (2001) 142:3935-40. doi: 10.1210/endo.142.9.8385

45. Brown RSE, Kokay IC, Herbison AE, Grattan DR. Distribution of prolactinresponsive neurons in the mouse forebrain. J Comp Neurol. (2010) 518:92102. doi: $10.1002 / \mathrm{cne} .22208$

46. Salais-López H, Lanuza E, Agustín-Pavón C, Martínez-García F. Tuning the brain for motherhood: prolactin-like central signalling in virgin, pregnant, and lactating female mice. Brain Struct Funct. (2017) 222:895-921. doi: $10.1007 /$ s00429-016-1254-5

47. Salais-López H, Abellan-Alvaro M, Bellés M, Lanuza E, AgustinPavon C, Martínez-García F. Maternal motivation: exploring the roles of prolactin and pup stimuli. Neuroendocrinology. (2020) 119:805-30. doi: $10.1159 / 000510038$

48. Oláh S, Cservenák M, Keller D, Fazekas EA, Renner É, Low P, et al. Prolactininduced and neuronal activation in the brain of mother mice. Brain Struct Funct. (2018) 223:3229-50. doi: 10.1007/s00429-018-1686-1

49. Brown RSE, Herbison AE, Grattan DR. Differential changes in responses of hypothalamic and brainstem neuronal populations to prolactin during lactation in the mouse. Biol Reprod. (2011) 84:826-36. doi: 10.1095/biolreprod.110.089185

50. Salais-López H, Agustín-Pavón C, Lanuza E, Martínez-García F. The maternal hormone in the male brain: Sexually dimorphic distribution of prolactin signalling in the mouse brain. Mintz EM, editor. PLoS ONE. (2018) 13:e0208960. doi: 10.1371/journal.pone.0208960

51. Lerant A, Freeman ME. Ovarian steroids differentially regulate the expression of PRL-R in neuroendocrine dopaminergic neuron populations: A double label confocal microscopic study. Brain Res. (1998) 802:141-54. doi: 10.1016/S0006-8993(98)00583-6

52. Kokay IC, Grattan DR. Expression of mRNA for prolactin receptor (long form) in dopamine and pro-opiomelanocortin neurones in the arcuate nucleus of non-pregnant and lactating rats. J Neuroendocrinol. (2005) 17:827-35. doi: 10.1111/j.1365-2826.2005.01374.x

53. Brown RSE, Kokay IC, Phillipps HR, Yip SH, Gustafson P, Wyatt $A$, et al. Conditional deletion of the prolactin receptor reveals functional subpopulations of dopamine neurons in the arcuate nucleus of the hypothalamus. J Neurosci. (2016) 36:9173-85. doi: 10.1523/JNEUROSCI.1471-16.2016

54. Lyons DJ, Hellysaz A, Broberger C. Prolactin regulates tuberoinfundibular dopamine neuron discharge pattern: Novel feedback control mechanisms in the lactotrophic axis. J Neurosci. (2012) 32:8074-83. doi: 10.1523/JNEUROSCI.0129-12.2012

55. Georgescu T, Ladyman SR, Brown RSE, Grattan DR. Acute effects of prolactin on hypothalamic prolactin receptor expressing neurones in the mouse. J Neuroendocrinol. (2020) 32:12908. doi: 10.1111/jne.12908

56. Brown RSE, Piet R, Herbison AE, Grattan DR. Differential actions of prolactin on electrical activity and intracellular signal transduction in hypothalamic neurons. Endocrinology. (2012) 153:2375-84. doi: 10.1210/en.2011-2005

57. Romano N, Yip SH, Hodson DJ, Guillou A, Parnaudeau S, Kirk S, et al. Plasticity of Hypothalamic Dopamine Neurons during Lactation Results in Dissociation of Electrical Activity and Release. J Neurosci. (2013) 33:4424-33. doi: 10.1523/JNEUROSCI.4415-12.2013

58. Patil MJ, Ruparel SB, Henry MA, Akopian AN. Prolactin regulates TRPV1, TRPA1, and TRPM8 in sensory neurons in a sex-dependent manner:
Contribution of prolactin receptor to inflammatory pain. Am J Physiol Endocrinol Metab. (2013) 305:1154-64. doi: 10.1152/ajpendo.00187.2013

59. Patil M, Belugin S, Mecklenburg J, Wangzhou A, Paige C, BarbaEscobedo PA, et al. Prolactin regulates pain responses via a femaleselective nociceptor-specific mechanism. iScience. (2019) 20:449-65. doi: 10.1016/j.isci.2019.09.039

60. Patil MJ, Henry MA, Akopian AN. Prolactin receptor in regulation of neuronal excitability and channels. Channels. (2014) 8:193-202. doi: $10.4161 /$ chan. 28946

61. Buonfiglio DC, Ramos-Lobo AM, Silveira MA, Furigo IC, Hennighausen L, Frazão R, et al. Neuronal STAT5 signaling is required for maintaining lactation but not for postpartum maternal behaviors in mice. Horm Behav. (2015) 71:60-8. doi: 10.1016/j.yhbeh.2015.04.004

62. Sirzen-Zelenskaya A, Gonzalez-Iglesias AE, Boutet de Monvel J, Bertram R, Freeman ME, Gerber U, et al. Prolactin induces a hyperpolarising current in rat paraventricular oxytocinergic neurones. J Neuroendocrinol. (2011) 23:883-93. doi: 10.1111/j.1365-2826.2011.02207.x

63. Augustine RA, Ladyman SR, Bouwer GT, Alyousif Y, Sapsford TJ, Scott V, et al. Prolactin regulation of oxytocin neurone activity in pregnancy and lactation. J Physiol. (2017) 595:3591-605. doi: 10.1113/JP273712

64. Kokay IC, Bull PM, Davis RL, Ludwig M, Grattan DR. Expression of the long form of the prolactin receptor in magnocellular oxytocin neurons is associated with specific prolactin regulation of oxytocin neurons. Am J Physiol - Regul Integr Comp Physiol. (2006) 290:1216-25. doi: 10.1152/ajpregu.00730.2005

65. Riddle O, Lahr EL, Bates RW. Maternal Behavior Induced in Virgin Rats by Prolactin. Exp Biol Med. (1935) 32:730-4. doi: 10.3181/00379727-32-7837C

66. Bridges RS, DiBiase R, Loundes DD, Doherty PC. Prolactin stimulation of maternal behavior in female rats. Science. (1985) 227:782LP-4. doi: 10.1126/science.3969568

67. Bridges RS, Numan M, Ronsheim PM, Mann PE, Lupini CE. Central prolactin infusions stimulate maternal behavior in steroid-treated, nulliparous female rats. Proc Natl Acad Sci USA. (1990) 87:8003-7. doi: 10.1073/pnas.87.20.8003

68. Bridges RS, Robertson MC, Shiu RPC, Sturgis JD, Henriquez BM, Mann PE. Central lactogenic regulation of maternal behavior in rats: Steroid dependence, hormone specificity, and behavioral potencies of rat prolactin and rat placental lactogen I. Endocrinology. (1997) 138:756-63. doi: 10.1210/endo.138.2.4921

69. Bridges RS, Rigero BA, Byrnes EM, Yang L, Walker AM. Central infusions of the recombinant human prolactin receptor antagonist, S179D-PRL, delay the onset of maternal behavior in steroid-primed, nulliparous female rats. Endocrinology. (2001) 142:730-9. doi: 10.1210/endo.142.2.7931

70. Lucas BK, Ormandy CJ, Binart N, Bridges RS, Kelly PA. Null mutation of the prolactin receptor gene produces a defect in maternal behavior. Endocrinology. (1998) 139:4102-7. doi: 10.1210/endo.139.10.6243

71. Larsen CM, Grattan DR. Prolactin-induced mitogenesis in the subventricular zone of the maternal brain during early pregnancy is essential for normal postpartum behavioral responses in the mother. Endocrinology. (2010) 151:3805-14. doi: 10.1210/en.2009-1385

72. Brown RSEE, Aoki M, Ladyman SR, Phillipps HR, Wyatt A, Boehm U, et al. Prolactin action in the medial preoptic area is necessary for postpartum maternal nursing behavior. Proc Natl Acad Sci USA. (2017) 114:201708025. doi: 10.1073/pnas.1708025114

73. Melo AI, Pérez-Ledezma M, Clapp C, Arnold E, Rivera JC, Fleming AS. Effects of prolactin deficiency during the early postnatal period on the development of maternal behavior in female rats: Mother's milk makes the difference. Horm Behav. (2009) 56:281-91. doi: 10.1016/j.yhbeh.2009.06.005

74. Swart JM, Grattan DR, Ladyman SR, Brown RSE. Changes in maternal motivation across reproductive states in mice: A role for prolactin receptor activation on GABA neurons. Horm Behav. (2021) 135:105041. doi: 10.1016/j.yhbeh.2021.105041

75. Gleason PE, Michael SD, Christian JJ. Brief report prolactin-induced aggression in female Peromyscus leucopus. Behav Neural Biol. (1981) 33:243-8. doi: 10.1016/S0163-1047(81)91703-9

76. Voci VE, Carlson NR. Enhancement of maternal behavior and nest building following systemic and diencephalic administration of prolactin 
and progesterone in the mouse. J Comp Physiol Psychol. (1973) 83:388-93. doi: 10.1037/h0034663

77. González-Mariscal G, Melo AI, Parlow AF, Beyer C, Rosenblatt JS. Pharmacological evidence that prolactin acts from late gestation to promote maternal behaviour in rabbits. J Neuroendocrinol. (2000) 12:983-92. doi: 10.1046/j.1365-2826.2000.00544.x

78. González-Mariscal G, Chirino R, Flores-Alfonso JC, Rosenblatt JS, Beyer C. Intracerebroventricular injections of prolactin counteract the antagonistic effect of bromocriptine on rabbit maternal behaviour. J Neuroendocrinol. (2004) 16:949-55. doi: 10.1111/j.1365-2826.2004.01253.x

79. Donner N, Bredewold R, Maloumby R, Neumann ID. Chronic intracerebral prolactin attenuates neuronal stress circuitries in virgin rats. Eur J Neurosci. (2007) 25:1804-14. doi: 10.1111/j.1460-9568.2007.05416.x

80. Torner L, Toschi N, Nava G, Clapp C, Neumann ID. Increased hypothalamic expression of prolactin in lactation: Involvement in behavioural and neuroendocrine stress responses. Eur J Neurosci. (2002) 15:1381-9. doi: 10.1046/j.1460-9568.2002.01965.x

81. Naef L, Woodside B. Prolactin/leptin interactions in the control of food intake in rats. Endocrinology. (2007) 148:5977-83. doi: 10.1210/en.2007-0442

82. Gerardo-Gettens T, Moore BJ, Stern JS, Horwitz BA. Prolactin stimulates food intake in a dose-dependent manner. Am J Physiol - Regul Integr Comp Physiol. (1989) 256:276-80. doi: 10.1152/ajpregu.1989.256.1.R276

83. Gerardo-Gettens T, Moore BJ, Stern JS, Horwitz BA. Prolactin stimulates food intake in the absence of ovarian progesterone. Am J Physiol Integr Comp Physiol. (1989) 256:R701-6. doi: 10.1152/ajpregu.1989.256.3.R701

84. Sauve D, Woodside B. Neuroanatomical specificity of prolactin-induced hyperphagia in virgin female rats. Brain Res. (2000) 868:306-14. doi: 10.1016/S0006-8993(00)02344-1

85. Ladyman SR, MacLeod MA, Khant Aung Z, Knowles P, Phillipps HR, Brown RSE, et al. Prolactin receptors in Rip-cre cells, but not in AgRP neurones, are involved in energy homeostasis. J Neuroendocrinol. (2017) 29:1-11. doi: $10.1111 /$ jne.12474

86. Ladyman SR, Carter KM, Gillett ML, Aung ZK, Grattan DR. A reduction in voluntary physical activity in early pregnancy in mice is mediated by prolactin. Elife. (2021) 10:1-25. doi: 10.7554/eLife.62260

87. Ormandy CJ, Camus A, Barra J, Damotte D, Lucas B, Buteau H, et al. Null mutation of the prolactin receptor gene produces multiple reproductive defects in the mouse. Genes Dev. (1997) 11:167-78. doi: 10.1101/gad.11.2.167

88. Stocco C, Telleria C, Gibori G. The molecular control of corpus luteum formation, function, and regression. Endocr Rev. (2007) 28:117-49. doi: 10.1210/er.2006-0022

89. Numan M. Motivational systems and the neural circuitry of maternal behavior in the rat. Dev Psychobiol. (2007) 49:12-21. doi: 10.1002/dev.20198

90. Dulac C, O'Connell LA, Wu Z. Neural control of maternal and paternal behaviors. Science. (2014) 345:765-70. doi: 10.1126/science.1253291

91. Numan M. Hypothalamic neural circuits regulating maternal responsiveness toward infants. Behav Cogn Neurosci Rev. (2006) 5:163-90. doi: $10.1177 / 1534582306288790$

92. Bakowska JC, Morrell JI. The distribution of mRNA for the short form of the prolactin receptor in the forebrain of the female rat. Mol Brain Res. (2003) 116:50-8. doi: 10.1016/S0169-328X(03)00213-4

93. Moffitt JR, Bambah-Mukku D, Eichhorn SW, Vaughn E, Shekhar $\mathrm{K}$, Perez JD, et al. Molecular, spatial, and functional single-cell profiling of the hypothalamic preoptic region. Science. (2018) 362:5324. doi: $10.1126 /$ science.aau5324

94. Gustafson P, Ladyman SR, McFadden S, Larsen C, Khant Aung Z, Brown RSE, et al. Prolactin receptor-mediated activation of PSTAT5 in the pregnant mouse brain. J Neuroendocrinol. (2020) 32:1-11. doi: 10.1111/jne.12901

95. Kohl J, Babayan BM, Rubinstein ND, Autry AE, Marin-Rodriguez B, Kapoor $\mathrm{V}$, et al. Functional circuit architecture underlying parental behaviour. Nature. (2018) 556:326-31. doi: 10.1038/s41586-018-0027-0

96. Shingo T, Gregg C, Enwere E, Fujikawa H, Hassam R, Geary C, et al. Pregnancy-stimulated neurogenesis in the adult female forebrain mediated by prolactin. Science. (2003) 299:117-20. doi: 10.1126/science.1076647

97. Furuta M, Bridges RS. Gestation-induced cell proliferation in the rat brain. Dev Brain Res. (2005) 156:61-6. doi: 10.1016/j.devbrainres.2005.01.008
98. Seip KM, Morrell JI. Exposure to pups influences the strength of maternal motivation in virgin female rats. Physiol Behav. (2008) 95:599-608. doi: 10.1016/j.physbeh.2008.09.003

99. Pereira M, Seip KM, Morrell JI. Chapter 3 - maternal motivation and its neural substrate across the postpartum period. In: Bridges RS, editor. Neurobiology of the Parental Brain. San Diego, CA: Academic Press (2008). p. 39-59. doi: 10.1016/B978-0-12-374285-8.00003-2

100. Mattson BJ, Williams S, Rosenblatt JS, Morrell JI. Comparison of two positive reinforcing stimuli: Pups and cocaine throughout the Postpartum period. Behav Neurosci. (2001) 115:683-94. doi: 10.1037/0735-7044.115.3.683

101. Fleming AS, Korsmit M, Deller M. Rat pups are potent reinforcers to the maternal animal: Effects of experience, parity, hormones, and dopamine function. Psychobiology. (1994) 22:44-53.

102. Seip KM, Morrell JI. Transient inactivation of the ventral tegmental area selectively disrupts the expression of conditioned place preference for pup- but not cocaine-paired contexts. Behav Neurosci. (2009) 123:1325-38. doi: $10.1037 / \mathrm{a} 0017666$

103. Pereira M, Morrell JI. The medial preoptic area is necessary for motivated choice of pup- over cocaine-associated environments by early postpartum rats. Neuroscience. (2010) 167:216-31. doi: 10.1016/j.neuroscience.2010.02.015

104. Fang YY, Yamaguchi T, Song SC, Tritsch NX, Lin D. A hypothalamic midbrain pathway essential for driving maternal behaviors. Neuron. (2018) 98:192-207.e10. doi: 10.1016/j.neuron.2018.02.019

105. Stolzenberg DS, Numan M. Hypothalamic interaction with the mesolimbic DA system in the control of the maternal and sexual behaviors in rats. Neurosci Biobehav Rev. (2011) 35:826-47. doi: 10.1016/j.neubiorev.2010.10.003

106. Stewart DE, Vigod SN. Postpartum depression: Pathophysiology, treatment, and emerging therapeutics. Annu Rev Med. (2019) 70:183-96. doi: 10.1146/annurev-med-041217-011106

107. O'Hara MW, Mc Cabe JE. Postpartum depression: Current status and future directions. Annu Rev Clin Psychol. (2013) 9:379-407. doi: 10.1146/annurev-clinpsy-050212-185612

108. Bartels A, Zeki S. The neural correlates of maternal and romantic love. Neuroimage. (2004) 21:1155-66. doi: 10.1016/j.neuroimage.2003.11.003

109. Nitschke JB, Nelson EE, Rusch BD, Fox AS, Oakes TR, Davidson RJ. Orbitofrontal cortex tracks positive mood in mothers viewing pictures of their newborn infants. Neuroimage. (2004) 21:583-92. doi: 10.1016/j.neuroimage.2003.10.005

110. Strathearn L, Li J, Fonagy P, Montague PR. What's in a smile? Maternal brain responses to infant facial cues. Pediatrics. (2008) 122:40-51. doi: 10.1542/peds.2007-1566

111. Morgan JK, Guo C, Moses-Kolko EL, Phillips ML, Stepp SD, Hipwell AE. Postpartum depressive symptoms moderate the link between mothers' neural response to positive faces in reward and social regions and observed caregiving. Soc Cogn Affect Neurosci. (2017) 12:1605-13. doi: $10.1093 /$ scan/nsx087

112. Laurent HK, Ablow JC. A face a mother could love: Depression-related maternal neural responses to infant emotion faces. Soc Neurosci. (2013) 8:228-39. doi: $10.1080 / 17470919.2012 .762039$

113. Laurent HK, Ablow JC. A cry in the dark: Depressed mothers show reduced neural activation to their own infant's cry. Soc Cogn Affect Neurosci. (2012) 7:125-34. doi: 10.1093/scan/nsq091

114. Bosch OJ. Maternal aggression in rodents: Brain oxytocin and vasopressin mediate pup defence. Philos Trans R Soc B Biol Sci. (2013) 368:85. doi: 10.1098/rstb.2013.0085

115. Haney M, Debold JF, Miczek KA. Maternal aggression in mice and rats towards male and female conspecifics. Aggress Behav. (1989) 15:443-53. doi: 10.1002/1098-2337 (1989) 15:6<443::AID-AB2480150605>3.0.CO;2-U

116. Gandelman R, Simon NG. Postpartum fighting in the rat: Nipple development and the presence of young. Behav Neural Biol. (1980) 28:35060. doi: 10.1016/S0163-1047(80)92357-2

117. Ylönen $\mathrm{H}$, Horne TJ. Infanticide and effectiveness of pup protection in bank voles: Does the mother recognise a killer? Acta Ethol. (2002) 4:97-101. doi: 10.1007/s10211-001-0055-9 
118. Wise DA. Aggression in the female golden hamster: Effects of reproductive state and social isolation. Horm Behav. (1974) 5:235-50. doi: 10.1016/0018-506X(74)90032-4

119. Grinnell J, McComb K. Maternal grouping as a defense against infanticide by males: Evidence from field playback experiments on African lions. Behav Ecol. (1996) 7:55-9. doi: 10.1093/beheco/7.1.55

120. Smith WP. Maternal defense in columbian white-tailed deer : when is it worth it? Am Nat. (1987) 130:310-6. doi: 10.1086/284712

121. Maestripieri D. Costs and benefits of maternal aggression in lactating female rhesus macaques. Primates. (1994) 35:443-53. doi: 10.1007/BF02381953

122. Hahn-Holbrook J, Holt-Lunstad J, Holbrook C, Coyne SM, Lawson ET. Maternal defense: breast feeding increases aggression by reducing stress. Psychol Sci. (2011) 22:1288-95. doi: 10.1177/0956797611420729

123. Mastrogiacomo I, Fava M, Fava GA, Kellner R, Grismondi G, Cetera C. Postpartum hostility and prolactin. Int J Psychiatry Med. (1982) 12:289-94. doi: 10.2190/6K03-E32R-NJA4-9C3F

124. Reavley S, Fisher AD, Owen D, Creed FH, Davis JRE. Psychological distress in patients with hyperprolactinaemia. Clin Endocrinol. (1997) 47:343-8. doi: 10.1046/j.1365-2265.1997.2701073.x

125. Hashikawa K, Hashikawa Y, Tremblay R, Zhang J, Feng JE, Sabol A, et al. Esr1+ cells in the ventromedial hypothalamus control female aggression. Nat Neurosci. (2017) 20:1580-90. doi: 10.1038/nn.4644

126. Unger EK, Burke KJ, Yang CF, Bender KJ, Fuller PM, Shah NM. Medial amygdalar aromatase neurons regulate aggression in both sexes. Cell Rep. (2015) 10:453-62. doi: 10.1016/j.celrep.2014.12.040

127. Svare B, Mann MA, Broida J, Michael SD. Maternal aggression exhibited by hypophysectomized parturient mice. Horm Behav. (1982) 16:455-61. doi: 10.1016/0018-506X(82)90052-6

128. Ou $\mathrm{CH}$, Hall WA. Anger in the context of postnatal depression: An integrative review. Birth. (2018) 45:336-46. doi: 10.1111/birt.12356

129. Bosch OJ, Meddle SL, Beiderbeck DI, Douglas AJ, Neumann ID. Brain oxytocin correlates with maternal aggression: Link to anxiety. J Neurosci. (2005) 25:6807-15. doi: 10.1523/JNEUROSCI.1342-05.2005

130. Gandelman R. Induction of maternal nest building in virgin female mice by the presentation of young. Horm Behav. (1973) 4:191-7. doi: 10.1016/0018-506X(73)90003-2

131. Zarrow MX, Gandelman R, Denenberg VH. Lack of nest building and maternal behavior in the mouse following olfactory bulb removal. Horm Behav. (1971) 2:227-38. doi: 10.1016/0018-506X(71)90020-1

132. Gandelman R, McDermott NJ, Kleinman M, DeJianne D. Maternal nest building by pseudopregnant mice. J Reprod Fertil. (1979) 56:697-9. doi: 10.1530/jrf.0.0560697

133. Douglas AJ, Brunton PJ, Bosch OJ, Russell JA, Neumann ID. Neuroendocrine responses to stress in mice: hyporesponsiveness in pregnancy and parturition. Endocrinology. (2003) 144:5268-76. doi: 10.1210/en.2003-0461

134. Li XY, Han Y, Zhang W, Wang SR, Wei YC, Li SS, et al. AGRP neurons project to the medial preoptic area and modulate maternal nest-building. J Neurosci. (2019) 39:456-71. doi: 10.1523/JNEUROSCI.0958-18.2018

135. Grabrucker S, Pagano J, Schweizer J, Urrutia-Ruiz C, Schön M, Thome K, et al. Activation of the medial preoptic area (MPOA) ameliorates loss of maternal behavior in a Shank2 mouse model for autism. EMBO J. (2021) 40:1-19. doi: 10.15252/embj.2019104267

136. Anderson M V., Rutherford MD. Evidence of a nesting psychology during human pregnancy. Evol Hum Behav. (2013) 34:390-7. doi: 10.1016/j.evolhumbehav.2013.07.002

137. Altemus M, Deuster PA, Galliven E, Carter CS, Gold PW. Suppression of hypothalmic-pituitary-adrenal axis responses to stress in lactating women. $J$ Clin Endocrinol Metab. (1995) 80:2954-9. doi: 10.1210/jcem.80.10.7559880

138. Lightman SL, Young WS. Lactation inhibits stress-mediated secretion of corticosterone and oxytocin and hypothalamic accumulation of corticotropin-releasing factor and enkephalin messenger ribonucleic acids. Endocrinology. (1989) 124:2358-64. doi: 10.1210/endo-124-5-2358

139. Hillerer KM, Reber SO, Neumann ID, Slattery DA. Exposure to chronic pregnancy stress reverses peripartum-associated adaptations: Implications for postpartum anxiety and mood disorders. Endocrinology. (2011) 152:3930-40. doi: 10.1210/en.2011-1091

140. Smith JW, Seckl JR, Evans AT, Costall B, Smythe JW. Gestational stress induces post-partum depression-like behaviour and alters maternal care in rats. Psychoneuroendocrinology. (2004) 29:227-44. doi: 10.1016/S0306-4530(03)00025-8

141. Li M, Chou SY. Modeling postpartum depression in rats: theoretic and methodological issues. Zool Res. (2016) 37:229-36. doi: 10.13918/j.issn.2095-8137.2016.4.229

142. Walsh K, McCormack CA, Webster R, Pinto A, Lee S, Feng T, et al. Maternal prenatal stress phenotypes associate with fetal neurodevelopment and birth outcomes. Proc Natl Acad Sci USA. (2019) 116:23996-4005. doi: $10.1073 /$ pnas. 1905890116

143. Soares-Cunha C, Coimbra B, Borges S, Domingues AV, Silva D, Sousa $\mathrm{N}$, et al. Mild prenatal stress causes emotional and brain structural modifications in rats of both sexes. Front Behav Neurosci. (2018) 12:129. doi: 10.3389/fnbeh.2018.00129

144. Jafari Z, Mehla J, Kolb BE, Mohajerani MH. Prenatal noise stress impairs HPA axis and cognitive performance in mice. Sci Rep. (2017) 7:1-13. doi: 10.1038/s41598-017-09799-6

145. Shanks N, Windle RJ, Perks $\mathrm{P}$, Wood S, Ingram CD, Lightman SL. The hypothalamic-pituitary-adrenal axis response to endotoxin is attenuated during lactation. J Neuroendocrinol. (1999) 11:857-65. doi: 10.1046/j.1365-2826.1999.00400.x

146. Kammerer M, Adams D, von Castelberg B, Glover V. Pregnant women become insensitive to cold stress. BMC Pregnancy Childbirth. (2002) 2:2-6. doi: 10.1186/1471-2393-2-8

147. Torner L, Toschi N, Pohlinger A, Landgraf R, Neumann ID. Anxiolytic and anti-stress effects of brain prolactin: Improved efficacy of antisense targeting of the prolactin receptor by molecular modeling. J Neurosci. (2001) 21:3207-14. doi: 10.1523/JNEUROSCI.21-09-03207.2001

148. Kim J, Lee S, Fang YY, Shin A, Park S, Hashikawa K, et al. Rapid, biphasic CRF neuronal responses encode positive and negative valence. Nat Neurosci. (2019) 22:576-85. doi: 10.1038/s41593-019-0342-2

149. Füzesi T, Daviu N, Wamsteeker Cusulin JI, Bonin RP, Bains JS. Hypothalamic CRH neurons orchestrate complex behaviours after stress. Nat Commun. (2016) 7:1-14. doi: 10.1038/ncomms11937

150. Kim JS, Han SY, Iremonger KJ. Stress experience and hormone feedback tune distinct components of hypothalamic CRH neuron activity. Nat Commun. (2019) 10:1-15. doi: 10.1038/s41467-019-13639-8

151. Weber RFA, Calogero AE. Prolactin stimulates rat hypothalamic corticotropin-releasing hormone and pituitary adrenocorticotropin secretion in vitro. Neuroendocrinology. (1991) 54:248-53. doi: 10.1159/000125882

152. Gustafson P, Bunn SJ, Grattan DR. The role of prolactin in the suppression of Crh mRNA expression during pregnancy and lactation in the mouse. $J$ Neuroendocrinol. (2017) 29:12511. doi: 10.1111/jne.12511

153. Gustafson P, Kokay I, Sapsford T, Bunn S, Grattan D. Prolactin regulation of the HPA axis is not mediated by a direct action upon CRH neurons: evidence from the rat and mouse. Brain Struct Funct. (2017) 222:3191-204. doi: 10.1007/s00429-017-1395-1

154. Dunkel Schetter C, Tanner L. Anxiety, depression and stress in pregnancy: Implications for mothers, children, research, and practice. Curr Opin Psychiatry. (2012) 25:141-8. doi: 10.1097/YCO.0b013e3283503680

155. Zietlow AL, Nonnenmacher N, Reck C, Ditzen B, Müller M. Emotional stress during pregnancy - Associations with maternal anxiety disorders, infant cortisol reactivity, and mother-child interaction at pre-school age. Front Psychol. (2019) 10:2179. doi: 10.3389/fpsyg.2019.02179

156. Reck C, Tietz A, Müller M, Seibold K, Tronick E. The impact of maternal anxiety disorder on mother-infant interaction in the postpartum period. PLoS ONE. (2018) 13:e0194763. doi: 10.1371/journal.pone.0194763

157. Fairbrother N, Janssen P, Antony MM, Tucker E, Young AH. Perinatal anxiety disorder prevalence and incidence. J Affect Disord. (2016) 200:14855. doi: 10.1016/j.jad.2015.12.082

158. Dennis CL, Falah-Hassani K, Shiri R. Prevalence of antenatal and postnatal anxiety: Systematic review and meta-analysis. Br J Psychiatry. (2017) 210:315-23. doi: 10.1192/bjp.bp.116.187179

159. Ladyman SR, Grattan DR. Region-specific reduction in leptin-induced phosphorylation of signal transducer and activator of transcription-3 (STAT3) in the rat hypothalamus is associated with leptin resistance during pregnancy. Endocrinology. (2004) 145:3704-11. doi: 10.1210/en.20040338 
160. Makarova EN, Kochubei ED, Bazhan NM. Regulation of food consumption during pregnancy and lactation in mice. Neurosci Behav Physiol. (2010) 40:263-7. doi: 10.1007/s11055-010-9253-0

161. Ladyman SR, Hackwell ECR, Brown RSE. The role of prolactin in co-ordinating fertility and metabolic adaptations during reproduction. Neuropharmacology. (2020) 167:107911. doi: 10.1016/ j.neuropharm.2019.107911

162. Moya J, Phillips L, Sanford J, Wooton M, Gregg A, Schuda L. A review of physiological and behavioral changes during pregnancy and lactation: Potential exposure factors and data gaps. J Expo Sci Environ Epidemiol. (2014) 24:449-58. doi: 10.1038/jes.2013.92

163. Woodside B. Prolactin and the hyperphagia of lactation. Physiol Behav. (2007) 91:375-82. doi: 10.1016/j.physbeh.2007.04.015

164. Ladyman SR, Carter KM, Grattan DR. Energy homeostasis and running wheel activity during pregnancy in the mouse. Physiol Behav. (2018) 194:8394. doi: 10.1016/j.physbeh.2018.05.002

165. Atasoy D, Betley JN, Su HH, Sternson SM. Deconstruction of a neural circuit for hunger. Nature. (2012) 488:172-7. doi: 10.1038/nature11270

166. Heisler LK, Lam DD. An appetite for life: brain regulation of hunger and satiety. Curr Opin Pharmacol. (2017) 37:100-6. doi: 10.1016/j.coph.2017.09.002

167. Timper K, Brüning JC. Hypothalamic circuits regulating appetite and energy homeostasis: Pathways to obesity. DMM Dis Model Mech. (2017) 10:679-89. doi: $10.1242 / \mathrm{dmm} .026609$

168. Sternson SM, Atasoy D. Agouti-related protein neuron circuits that regulate appetite. Neuroendocrinology. (2014) 100:95-102. doi: 10.1159/000369072

169. Andermann ML, Lowell BB. Toward a wiring diagram understanding of appetite control. Neuron. (2017) 95:757-78. doi: 10.1016/j.neuron.2017.06.014

170. Wang D, He X, Zhao Z, Feng Q, Lin R, Sun Y, et al. Whole-brain mapping of the direct inputs and axonal projections of POMC and AgRP neurons. Front Neuroanat. (2015) 9:40. doi: 10.3389/fnana.2015.00040

171. Ladyman SR, Fieldwick DM, Grattan DR. Suppression of leptin-induced hypothalamic JAK/STAT signalling and feeding response during pregnancy in the mouse. Reproduction. (2012) 144:83-90. doi: 10.1530/REP-12-0112

172. Augustine RA, Grattan DR. Induction of central leptin resistance in hyperphagic pseudopregnant rats by chronic prolactin infusion. Endocrinology. (2008) 149:1049-55. doi: 10.1210/en.2007-1018

173. Smith MS. Lactation alters neuropeptide- $Y$ and proopiomelanocortin gene expression in the arcuate nucleus of the rat. Endocrinology. (1993) 133:125865. doi: 10.1210/endo.133.3.8365368

174. Wilding JPH, Ajala MO, Lambert PD, Bloom SR. Additive effects of lactation and food restriction to increase hypothalamic neuropeptide $\mathrm{Y}$ mRNA in rats. J Endocrinol. (1997) 152:365-9. doi: 10.1677/joe.0.1520365

175. Malabu UH, Kilpatrick A, Ware M, Vernon RG, Williams G. Increased neuropeptide $\mathrm{Y}$ concentrations in specific hypothalamic regions of lactating rats: Possible relationship ot hyperphagia and adaptive changes in energy balance. Peptides. (1994) 15:83-7. doi: 10.1016/0196-9781(94)90174-0

176. Nahi F, Arbogast LA. Prolactin modulates hypothalamic preproenkephalin, but not proopiomelanocortin, gene expression during lactation. Endocrine. (2003) 20:115-22. doi: 10.1385/ENDO:20:1-2:115

177. Yang L, Scott KA, Hyun J, Tamashiro KL, Tray N, Moran TH, et al. Role of dorsomedial hypothalamic neuropeptide $\mathrm{Y}$ in modulating food intake and energy balance. $J$ Neurosci. (2009) 29:179-90. doi: 10.1523/JNEUROSCI.4379-08.2009

178. Bi S, Kim YJ, Zheng F. Dorsomedial hypothalamic NPY and energy balance control. Neuropeptides. (2012) 46:309-14. doi: 10.1016/j.npep.2012.09.002

179. Chen P, Smith MS. Regulation of hypothalamic neuropeptide y messenger ribonucleic acid expression during lactation: role of prolactin. Endocrinology. (2004) 145:823-9. doi: 10.1210/en.2003-1255

180. Harrison AL, Taylor NF, Shields N, Frawley HC. Attitudes, barriers and enablers to physical activity in pregnant women: a systematic review. J Physiother. (2018) 64:24-32. doi: 10.1016/j.jphys.2017. 11.012

181. Yang W, Han F, Gao X, Chen Y, Ji L, Cai X. Relationship between gestational weight gain and pregnancy complications or delivery outcome. Sci Rep. (2017) 7:1-9. doi: 10.1038/s41598-017-12921-3
182. Lovic V, Gonzalez A, Fleming AS. Maternally separated rats show deficits in maternal care in adulthood. Dev Psychobiol. (2001) 39:19-33. doi: $10.1002 /$ dev.1024

183. Gonzalez A, Lovic V, Ward GR, Wainwright PE, Fleming AS. Intergenerational effects of complete maternal deprivation and replacement stimulation on maternal behavior and emotionality in female rats. Dev Psychobiol. (2001) 38:11-32. doi: 10.1002/1098-2302(2001)38:1<11::aid-dev2>3.0.co;2-b

184. Sairenji TJ, Ikezawa J, Kaneko R, Masuda S, Uchida K, Takanashi Y, et al. Maternal prolactin during late pregnancy is important in generating nurturing behavior in the offspring. Proc Natl Acad Sci USA. (2017) 114:13042-7. doi: 10.1073/pnas.1621196114

185. Champagne FA. Epigenetic mechanisms and the transgenerational effects of maternal care. Front Neuroendocrinol. (2008) 29:386-97. doi: 10.1016/j.yfrne.2008.03.003

186. Morel GR, Carón RW, Cónsole GM, Soaje M, Sosa YE, Rodríguez SS, et al. Estrogen inhibits tuberoinfundibular dopaminergic neurons but does not cause irreversible damage. Brain Res Bull. (2009) 80:347-52. doi: 10.1016/j.brainresbull.2009.08.026

187. Lyons DJ, Horjales-Araujo E, Broberger C. Synchronized network oscillations in rat tuberoinfundibular dopamine neurons: switch to tonic discharge by thyrotropin-releasing hormone. Neuron. (2010) 65:217-29. doi: 10.1016/j.neuron.2009.12.024

188. Lyons DJ, Ammari R, Hellysaz A, Broberger C. Serotonin and Antidepressant SSRIs inhibit rat neuroendocrine dopamine neurons: parallel actions in the lactotrophic axis. J Neurosci. (2016) 36:7392-406. doi: 10.1523/JNEUROSCI.4061-15.2016

189. Aquino NSS, Araujo-Lopes R, Henriques PC, Lopes FEF, Gusmao DO, Coimbra CC, et al. $\alpha$-estrogen and progesterone receptors modulate Kisspeptin effects on prolactin: Role in estradiol-induced prolactin surge in female rats. Endocrinology. (2017) 158:1812-26. doi: 10.1210/en.2016-1855

190. Briffaud V, Williams P, Courty J, Broberger C. Excitation of tuberoinfundibular dopamine neurons by oxytocin: Crosstalk in the control of lactation. J Neurosci. (2015) 35:4229-37. doi: 10.1523/JNEUROSCI.2633-14.2015

191. Zhang X, van den Pol AN. Dopamine/tyrosine hydroxylase neurons of the hypothalamic arcuate nucleus release GABA, communicate with dopaminergic and other arcuate neurons, and respond to dynorphin, met-enkephalin, and oxytocin. J Neurosci. (2015) 35:14966-82. doi: 10.1523/JNEUROSCI.0293-15.2015

192. Egli M, Bertram R, Sellix MT, Freeman ME. Rhythmic secretion of prolactin in rats: Action of oxytocin coordinated by vasoactive intestinal polypeptide of suprachiasmatic nucleus origin. Endocrinology. (2004) 145:3386-94. doi: $10.1210 /$ en.2003-1710

193. Benson GK, Folley SJ. Oxytocin as stimulator for the release of prolactin from the anterior pituitary. Nature. (1956) 177:700. doi: 10.1038/177700a0

194. D’Anna KL, Gammie SC. Hypocretin-1 dose-dependently modulates maternal behaviour in mice. J Neuroendocrinol. (2006) 18:553-66. doi: $10.1111 / j .1365-2826.2006 .01448 . x$

195. Lyons DJ, Hellysaz A, Ammari R, Broberger C. Hypocretin/orexin peptides excite rat neuroendocrine dopamine neurons through orexin 2 receptormediated activation of a mixed cation current. Sci Rep. (2017) 7:1-12. doi: $10.1038 /$ srep 41535

196. Rivas M, Serantes D, Peña F, González J, Ferreira A, Torterolo P, et al. Role of hypocretin in the medial preoptic area in the regulation of sleep, maternal behavior and body temperature of lactating rats. Neuroscience. (2021) 475:148-62. doi: 10.1016/j.neuroscience.2021.08.034

197. Kamberi IA, Mical RS, Porter JC. Effects of melatonin and serotonin on the release of FSH and prolactin. Endocrinology. (1971) 88:1288-93. doi: 10.1210/endo-88-6-1288

198. Angoa-Pérez M, Kane MJ, Sykes CE, Perrine SA, Church MW, Kuhn DM. Brain serotonin determines maternal behavior and offspring survival. Genes Brain Behav. (2014) 13:579-91. doi: 10.1111/gbb.12159

199. Muzerelle A, Soiza-Reilly M, Hainer C, Ruet PL, Lesch KP, Bader M, et al. Dorsal raphe serotonin neurotransmission is required for the expression of nursing behavior and for pup survival. Sci Rep. (2021) 11:1-14. doi: 10.1038/s41598-021-84368-6 
200. Barofsky AL, Taylor J, Massari VJ. Dorsal raphe-hypothalamic projections provide the stimulatory serotonergic input to suckling-induced prolactin release. Endocrinology. (1983) 113:1894-903. doi: 10.1210/endo-113-5-1894

201. Lonstein JS. The dynamic serotonin system of the maternal brain. Arch Womens Ment Health. (2019) 22:237-43. doi: 10.1007/s00737-018-0887-1

202. Pedersen CA, Ascher JA, Monroe YL, Prange AJ. Oxytocin induces maternal behavior in virgin female rats. Science. (1982) 216:648-50. doi: $10.1126 /$ science. 7071605

203. Marlin BJ, Mitre M, D'Amour JA, Chao M V., Froemke RC. Oxytocin enables maternal behaviour by balancing cortical inhibition. Nature. (2015) 520:499-504. doi: 10.1038/nature14402

204. DeVries AC, Young WS, Nelson RJ. Reduced aggressive behaviour in mice with targeted disruption of the oxytocin gene. J Neuroendocrinol. (1997) 9:363-8. doi: 10.1046/j.1365-2826.1997.t01-1-00589.x

205. Townsend J, Cave BJ, Norman MR, Flynn A, Uney JB, Tortonese DJ, et al. Effects of prolactin on hypothalamic supraoptic neurones: evidence for modulation of STAT5 expression and electrical activity. Neuro Endocrinol Lett. (2005) 26:125-30.

206. Moltz H, Lubin M, Leon M, Numan M. Hormonal induction of maternal behavior in the ovariectomized nulliparous rat. Physiol Behav. (1970) 5:13737. doi: 10.1016/0031-9384(70)90122-8

207. Ribeiro AC, Musatov S, Shteyler A, Simanduyev S, Arrieta-Cruz I, Ogawa S, et al. siRNA silencing of estrogen receptor- $\alpha$ expression specifically in medial preoptic area neurons abolishes maternal care in female mice. Proc Natl Acad Sci USA. (2012) 109:16324-9. doi: 10.1073/pnas.1214094109

208. Pi X, Zhang B, Li J, Voogt JL. Promoter usage and estrogen regulation of prolactin receptor gene in the brain of the female rat. Neuroendocrinology. (2003) 77:187-97. doi: 10.1159/000069510

209. Anderson GM, Kieser DC, Steyn FJ, Grattan DR. Hypothalamic prolactin receptor messenger ribonucleic acid levels, prolactin signaling, and hyperprolactinemic inhibition of pulsatile luteinizing hormone secretion are dependent on estradiol. Endocrinology. (2008) 149:1562-70. doi: $10.1210 /$ en.2007-0867
210. Sheehan T, Numan M. Estrogen, progesterone, and pregnancy termination alter neural activity in brain regions that control maternal behavior in rats. Neuroendocrinology. (2002) 75:12-23. doi: 10.1159/0000 48217

211. Bridges RS, Hays LE. Steroid-induced alterations in mRNA expression of the long form of the prolactin receptor in the medial preoptic area of female rats: Effects of exposure to a pregnancy-like regimen of progesterone and estradiol. Mol Brain Res. (2005) 140:10-6. doi: 10.1016/j.molbrainres.2005.06.011

212. Zakar T, Hertelendy F. Progesterone withdrawal: key to parturition. Am J Obstet Gynecol. (2007) 196:289-96. doi: 10.1016/j.ajog.2006. 09.005

213. Grattan DR. 60 years of neuroendocrinology: The hypothalamo-prolactin axis. J Endocrinol. (2015) 226:T101-22. doi: 10.1530/JOE-15-0213

Conflict of Interest: The authors declare that the research was conducted in the absence of any commercial or financial relationships that could be construed as a potential conflict of interest.

Publisher's Note: All claims expressed in this article are solely those of the authors and do not necessarily represent those of their affiliated organizations, or those of the publisher, the editors and the reviewers. Any product that may be evaluated in this article, or claim that may be made by its manufacturer, is not guaranteed or endorsed by the publisher.

Copyright (๑) 2021 Georgescu, Swart, Grattan and Brown. This is an open-access article distributed under the terms of the Creative Commons Attribution License (CC $B Y)$. The use, distribution or reproduction in other forums is permitted, provided the original author(s) and the copyright owner(s) are credited and that the original publication in this journal is cited, in accordance with accepted academic practice. No use, distribution or reproduction is permitted which does not comply with these terms. 